\title{
As a critical behavior to improve quality and patient safety in health care: speaking up!
}

Ahmet Nacioglu ${ }^{1,2}$ (D)

\begin{abstract}
Introduction: Joint Commission predicted that $80 \%$ of the serious safety events occur due to miscommunications among healthcare professionals. Speaking up is one of the critical behaviors of patient safety that displays an important role for improving quality and patient safety in healthcare.

Objectives of this study are 'assessing the effectiveness of speaking up for patient safety', 'identifying the influencing factors of speaking up', 'evaluating the effectiveness of speaking up training' and 'finding enablers of speaking up'.

Methods: This study was done to identify literature about 'speaking up' behaviors to improve safety outcomes via considering both patient and provider perspectives. Varied databases were used to find English articles that relevant to both patient and provider's speaking up behaviors that mainly focused to demonstrate its impact on patient safety outcomes. Data was extracted and analyzed to find influencing factors and recommended voicing up behaviors that display important role for improvement in quality and safety of healthcare.
\end{abstract}

Results: 53 relevant articles were identified in 83 articles. Those 53 articles consist of 4 literature reviews, 3 RCTs, 8 cohorts, 1 case control, 34 cross sectional studies and 3 reports. This study is the first study about not just identifying factors that influencing speaking up behaviors among providers but also including factors of patients' voicing up behaviors for safety. This study is also providing some 'enablers of speaking up behaviors' which may help healthcare leaders and professionals' decision making process for quality and safety improvements in their organization.

Conclusions: Speaking up is one of the critical behaviors of patient safety. Awareness of factors that 'influencing' and 'enabling' speaking up behaviors may help leaders and decision makers to improve quality and safety of healthcare in their organization. This study is providing complex process of speaking up behavior and their impacts on patient safety outcomes.

Keywords: Speak up, Speaking up behaviors, Safety behaviors, Patient safety, Unsafe event, Safety event, Human factors in patient safety, Safety culture

\section{Background}

\section{Quality in health care: patient safety}

One of the definition of the quality is that doing something excellence or degree of excellence in specific field [1]. Inappropriateness of the Quality Control and Quality Assurance model which focus on inspection created need for more comprehensive model which called Total Quality Management (TQM) in Manufacturing Industry. As a comparison to the previous approaches, TQM is more comprehensive, participative and preventive. Changes and improvements in manufacturing, aviation and nuclear industries have led health organizations to provide safer care for their patients. Several institutions and studies identified six dimensions of quality in healthcare $[2,3]$. They are safety, efficiency, access (timeliness), efficacy, equity (appropriateness) and patient centeredness (consumer participation). One of the high quality of healthcare indicators relies on safety. World Health Organization (WHO) defined patient safety as "the absence of preventable harm to a patient during the process of healthcare" [4].

\section{Unsafe events and their categorizations}

Previously, medical incidents were called errors and medical errors can refer to 'wrong action or failures in planned care'
${ }^{1}$ School of Public Health, Li Ka Shing Faculty of Medicine, The University of Hong Kong, 5/F William MW Mong Block, Faculty of Medicine Building, 21 Sassoon Road, Pokfulam, Hong Kong

${ }^{2}$ Flat B, 2/F, Ming Garden, 46-48, Robinson Road, Pokfulam, Hong Kong 
or 'implementing wrong care plan to the patient'. Furthermore, medical error was defined as "an unintended health care outcome caused by a defect in the delivery of care to a patient" by National Patient Safety Foundation in Australia [5]. More recently, errors have started to be called as "unsafe events". Broader understanding of unsafe event's etiology and better classification of the unsafe event were done by psychologist James Reason (Fig. 1). Recent International Forums on Quality and Patient Safety in Healthcare and Institute for Healthcare Improvement (IHI) have taken up those understanding and classification of unsafe event that help providers for better understanding of unsafe events.

Safety issues are more likely to occur in intensive care units, operating rooms and emergency services $[5,6]$. In addition to these safety problems there are non-clinical issues which considered as operational risk factors such as: manpower, medical supplies- product quality, patient transfer, occupational safety and health (OSH), facilities defects, data security \& confidentiality, equipment failure, hospital security, fire safety and financial issues [5].

After IOM report released in 1999, most of health care organizations focused to prevention of medical errors however experts from most recent safety forums have suggested understanding of why these unsafe event occurs in health industry. In order to prevent errors and harm, professionals should understand error causation to prevent these unsafe events and address complex issues in system. Psychologist James Reason, to facilitate learning and identifying, he defined unsafe acts via dividing them to four groups: slips, lapses, mistakes, and violations (Fig. 1).

Unsafe act can be error or a violation that committed in the existence of a potential risk [7]. According to WHO, violation is defined as "a deliberate deviation from an operating procedure, standard, or rules" however such violations may occur and the intentions may not be causing harm [8]. Errors are whether mistakes (rule based, knowledge based), lapses or slips. Human

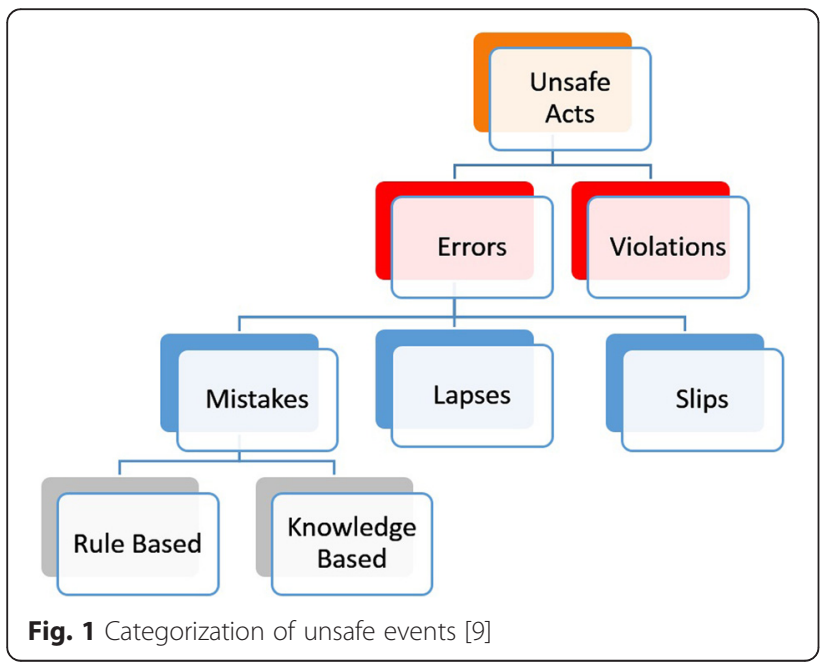

failures are an actions that may "not go as intended" or "go as intended, but it is wrong". For the action that doesn't go as intended, it might be observable slip or unobservable lapse. On the other hand, action which goes as intended but it is wrong, so called as a mistake that involves failure in planning process. Mistakes are either rule based which provider has knowledge but applies it wrong or knowledge based that provider doesn't have required knowledge for responding.

\section{The shift in approaching and understanding of patient safety issues}

The previous perspective for underlying factors of unsafe event focused to complexity of the health system and blamed individual (providers) for causing errors. After several researches and evaluations were conducted, professionals saw that blaming, naming and shaming approaches do not help to improve patient safety outcomes. After 15 years of IMO report, when providers were being understood that they do not intend to cause harm on patients, then the perspective has started to shift from individual level to system failures. They realize that most errors cannot be linked to the individual performance and these issues are mostly results of a series of preventable system errors. Redesigning systems to prevent errors and violations may help healthcare organization to improve the system and have better human condition and the conditions under which humans work.

\section{Human factors and changing behaviors of providers}

"Human factors" are discipline of engineering that deals with the interface of people, equipment, and the environment in which professional perform their duties. There are internal and external factors that affect human performance. These several circumstances influence human performance and increase risk of occurrence of unsafe events. Mental and physiological states, such as: fatigue, stress, dehydration, hunger, and boredom are playing role before the unsafe event occur. On the other hand, perception, attention, memory, reasoning, and judgment directly influence decision making process. Lastly, communication and being able to carry out the intended action are factors that directly increase possibility of decision execution.

Behaviors of provider may play essential role to improve safety for patients. Absence of safe behaviors in healthcare can lead to patient harm. The way to prevent errors is not to tell people to be more careful and work harder, it is changing the systems in which they work. As James Reason's teaching of latent errors: those "accidents waiting to happen" because of defects in the design of the systems in which people work. So that, WHO suggests using human factors principles to understand relationships between humans-humans, humans-medical equipment and humans-environment [9]. Well designed processes may make it easy for people to do the right things, and hard to 
do the wrong things. Multiple factors, which affect 'brain processes and responds' and influence 'personal performance' negatively, need to be prevented and mitigated for intended safety outcomes.

\section{Critical behaviors of healthcare staff: speaking up!}

There are four critical behaviors which are under our control that help to improve patient safety. They were classified by IHI as [10]:

- Following safety protocols

- Speak up when you have concerns

- Communicate effectively

- Take care of yourself

Joint Commission predicted that $80 \%$ of the serious safety events occur due to miscommunications among professionals. 'Speaking up' is one of the critical behaviors of patient safety that both provider and patient have ability to improve it. It is defined as raising of concerns by professionals or patients in existence of recognized deficient or risky actions that affect patient safety and quality of care [11]. It may display essential role in preventing and mitigating unsafe event which is causing harm on patient.

\section{Public health significance}

According to the IOM report in 1999, medical errors cost $\$ 29$ billion and least 44, 000 people; however more than 98,000 deaths occur as results of medical errors every year and burden of the medical errors exceed the sum of the burden of vehicle accidents, breast cancer and AIDS in the United States $[6,12]$. Some studies present that 1 in 3 Americans have experienced medical incidents while seeking care for their selves or their relatives [13].

Apart from US, WHO highlighted that [14]:

- Almost, 1 in 10 hospital patients is harmed while receiving care in developed countries.

- Hospital infections influence 14 of every 100 hospital admissions. As a result, 1.4 million people suffer from hospital-acquired infections in the world.

- Unsafe injections can cause 1.3 million deaths every year.

- In some countries, as many as $70 \%$ of injections are done with unsterilized syringes or needles.

- Poor quality in healthcare could result with $20 \%-40 \%$ waste. So that, studies demonstrate that improving patient safety could save some countries between $\$ 6$ and $\$ 29$ billion annually.

Safety events may occur between 3.7-16\% and avoidable harm expected to be $10 \%$ of events [15]. In one of the survey (n: 192,462), results showed that $53 \%$ of professionals afraid to raise a question when something did not seems right during procedure [16]. Unsafe events are not just causing lost income, household productivity, physical and psychological discomfort on patient but also resulting with such impacts on caregivers, providers and patient families. Healthcare organizations should seek solutions to mitigate these unsafe acts for better safety outcomes and ensure that their patients are safe during admission, diagnosis, treatment and discharge processes.

\section{Objective}

The objective of the literature review is to determine the evidence of the role of "speaking up" as a safety behavior in healthcare.

\section{Methods}

\section{Search strategy}

A literature search was conducted mainly using PubMed to find articles which were relevant to patient safety and speaking up behaviors of both patient and provider and published up to January 2016. A systematic search of articles and reports was performed by using key words of "Speak Up", "Speaking up", "Speaking up Behaviors", "Safety Behaviors", "Patient Safety", "Unsafe Event", "Safety Event", "Inter-professional Relations", "Human Factors in Patient Safety" and "Safety Culture". Several institutions' websites such as: World Health Organization (WHO), The Institute for Safe Medication Practices, The Joint Commission, Canadian Patient Safety Institute, Australian Patient Safety Foundation, Institute for Innovation and Improvement (UK), Patient Safety Resource Centre (UK), Institute for Healthcare Improvement (IHI), Agency for Healthcare Research and Quality, The International Society for Quality in Health Care and Safety Division, HA, HKSAR.

\section{Inclusion criteria}

- Articles were selected if their subjects were physicians, nurses, medical residents, fellows, experts in field, interns (medical field) and patients. Articles were included if they studied speaking up behaviors relevant to patient safety.

- Studies were included if they are meta-analysis, systematic review and observational studies.

- Relevant articles were included if they studied "Speak Up", "Speaking up", "Speaking up Behaviors" and "Safety Behaviors" in healthcare field.

- Not only the selected studies but also their references were scanned. Their relevant parts were included for the project.

- Regardless of types of study (observational and experimental), relevant articles were included.

\section{Exclusion criteria}

Articles not involving same objectives of this literature review and unrelated to the objectives of the review were 
excluded. Studies with outcomes of interest other than "Speak Up", "Speaking up", "Speaking up Behaviors" and "Safety Behaviors" were also excluded. When there were studies that cannot be discarded due to their initial screening of the title and abstract, their full texts were reviewed. After reviewing, their potential contributions (regarding to associations with purpose of the research) were assessed.

\section{Data collection method}

Studies were extracted through list of keywords mentioned in the beginning of the project. Articles which were not relevant to inclusion and exclusion criteria were discarded.

\section{Quality assessment criteria}

Checklist of Standards for Quality Improvement Reporting Excellence was used for the assessment of studies [17]. The
SQUIRE guidelines are beneficial for authors to make sense about writing excellent and usable articles related to quality improvement in healthcare field.

\section{Results}

\section{Findings}

53 relevant articles were identified in 83 articles. 4 literature reviews, 3 RCTs, 8 cohorts, 1 case control, 34 Cross Sectional studies and 3 reports were identified. More than half of the studies (32) came from United States while others from UK (7), Switzerland (4), New Zealand (2), Canada (2), Hong Kong (1), S. Korea (1), Ireland (1), Japan (1) and Iran (1). Most of the selected studies based on interviews and surveys results. Most of the studies mentioned speaking up behaviors of healthcare staff while four of them mentioned patient speaking up behaviors (Fig. 2) (Table 1).

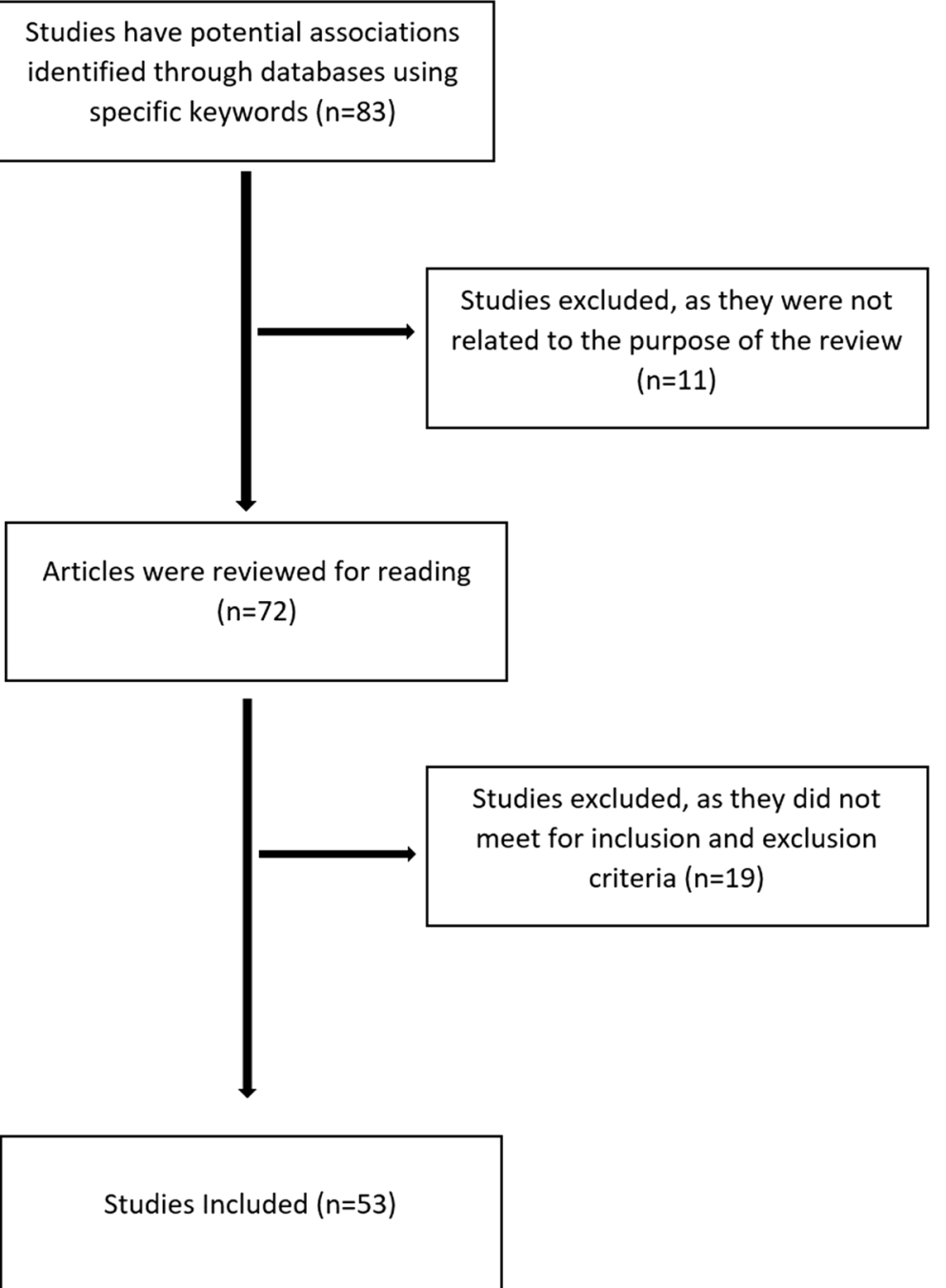

Fig. 2 Study selection process 
Table 1 Summary of studies

\begin{tabular}{|c|c|c|c|c|c|c|}
\hline $\begin{array}{l}\text { Reference } \\
\text { number }\end{array}$ & Author(s) and study year & Study type & Country & $\begin{array}{l}\text { Number of the Respondents/ } \\
\text { Participants/Cases/Reports/ } \\
\text { Scenarios }\end{array}$ & Study topic & Results/Findings \\
\hline [27] & Szymczak J.E., (2015) & Cross Sectional & US & $\begin{array}{l}\text { n: } 103 \text { Interviews with } \\
\text { clinicians }\end{array}$ & $\begin{array}{l}\text { Infections and interaction } \\
\text { rituals in the organization: } \\
\text { Clinician accounts of speaking } \\
\text { up or remaining silent in the } \\
\text { face of threats to patient safety }\end{array}$ & $\begin{array}{l}\text { There are three influences on the } \\
\text { decision to speak up that shaped } \\
\text { by background conditions in the } \\
\text { organization such as; mutual focus of } \\
\text { attention, interactional path } \\
\text { dependence and the presence of } \\
\text { an audience. According to the } \\
\text { findings, the decision to speak up in } \\
\text { a clinical setting is dynamic, highly } \\
\text { context-dependent, embedded in } \\
\text { the interaction rituals that suffuse } \\
\text { everyday work and constrained by } \\
\text { organizational dynamics in } \\
\text { healthcare. That article helps to } \\
\text { understand of the reasons why } \\
\text { speaking up in health care } \\
\text { organization is not easy as } \\
\text { thought. }\end{array}$ \\
\hline [34] & $\begin{array}{l}\text { Yule S., Parker H. S., Wilkinson J., } \\
\text { McKinley A., MacDonald J., } \\
\text { Neill A., McAdam T., (2015) }\end{array}$ & $\mathrm{RCT}$ & US & n:16 (surgical residents) & $\begin{array}{l}\text { Coaching Non-Technical skills } \\
\text { Improves Surgical Residents' } \\
\text { Performance in a simulated } \\
\text { Operating Room }\end{array}$ & $\begin{array}{l}\text { Non-technical skills such as situation } \\
\text { awareness, decision making, } \\
\text { teamwork and leadership are } \\
\text { critical for patient safety in the OR. } \\
\text { Non- technical skills improved in the } \\
\text { intervention group compared to } \\
\text { those in control group (p: 0.04). } \\
\text { Intervention group was faster to } \\
\text { respond unstoppable bleeding } \\
\text { (p: 0.03) }\end{array}$ \\
\hline [56] & Rosenstein H. A. (2015) & Progress Report & US & $\mathrm{n} / \mathrm{a}$ & $\begin{array}{l}\text { Physician Disruptive Behaviors: } \\
\text { Five Year Progress Report }\end{array}$ & $\begin{array}{l}\text { Disruptive behaviors in healthcare } \\
\text { can have a significant adverse effect } \\
\text { on staff interactions that can } \\
\text { negatively impact staff satisfactions, } \\
\text { staff performances and patient } \\
\text { outcomes of care. }\end{array}$ \\
\hline [19] & Ulrich B., Kear T., (2015) & Cross Sectional & US & n: 979 (nephrology nurses) & $\begin{array}{l}\text { Patient Safety Culture in } \\
\text { Nephrology Nurse Practice } \\
\text { Settings: Initial Findings }\end{array}$ & $\begin{array}{l}\text { Results demonstrated that there is } \\
\text { high rated teamwork among } \\
\text { colleagues but also, there is a } \\
\text { continued need for communication, } \\
\text { additional education, medication } \\
\text { safety and prioritization in practice. } \\
\text { For the results of communication } \\
\text { openness: the statement of "Staff } \\
\text { will freely speak up if they see } \\
\text { something may negatively } \\
\text { affect patient care," } 23 \% \text { were rated as } \\
\text { 'always' while } 44 \% \text { of the respondents } \\
\text { indicated as 'most of the time' } 67 \%\end{array}$ \\
\hline
\end{tabular}

Yule S, Parker H. S, Wilkinson J. McKinley A., MacDonald J. Neill A., McAdam T., (2015)

Rosenstein H. A. (2015)

Ulrich B., Kear T., (2015)
Cross Sectional US
Safety Culture in Nephrology Nurse Practice Settings: Initial Findings 
The experience of learning to speak up: a narrative inquiry on newly graduated registered nurses

(a)

Clinical human factors: the need to speak up to improve patient safety

Cross Sectional Switzerland n:759 (nurses and doctors) Frequency of and predictors for withholding patient safety positive response which is less than the AHRQ average of $76 \%$ ). Also 605 of the respondents highlighted that they were informed about errors that happen in their unit (it is also below the average of AHRQ of $67 \%$ in 2014). The reasons of miss reporting safety events by

nurses and patient care technicians were lack of time, cumbersome

documentation systems, lack of managerial support or follow up for an event and actual or perceived punishment towards the employee reporting an event.

The study result demonstrated the complex process of learning to speak up schematically. Three threads were found essential and these are:

1) learning to speak up requires more than one-off training and safety tools 2) mentoring speaking up in the midst of educative and miseducative experiences and 3) making public spaces safe for telling secret stories.

Speaking up is responsibility of everyone in the team. It is not essential just for operating theatre but also applicable to any other relevant situations in health organization. It is obviously needed when staff and patient are at risk or vulnerable, and when the team members have lack of awareness. Speaking up is an essential action considered belong professional accountability. concerns among oncology staff: a survey study
$70 \%$ of the staff had chosen to remain silent when they had concerns about patient safety for least once in the past. $37 \%$ of the staff also remained silent when they have information to prevent safety event at least once. Respondents highlighted that leve of interpersonal communication and coping with skills are important to speak up about safety event. to speak up about safety event. assertiveness, resilience and 
Table 1 Summary of studies (Continued)

Schwappach D.L.B., Gehring K., (2014)

Lyndon A., Johnson M.C.,

Bingham D., Napolitani P.G.

Joseph G., Maxfield D.G.,

O'Keeffle D.F. (2015)
Cross Sectional US

US

n: 3282 (physicians, nurses and midwifes)

Transforming communication and safety culture in intrapartum care: a multiorganization blueprint

frustration tolerance are required

for openness to speak up.

Silence that can be dangerous: a vignette study to assess healthcare professionals' likelihood of speaking up about safety concerns

missed hand disinfection, speaking up was significantly higher among managerial staff. Compared to senior staff, junior staff had two times discomfort about speaking up. Likelihood of speaking up was strongly influenced by contextual factors and seniority of the actor. It was also influenced by clinica frames, the level of perceived potential harm and decision difficulty. As an expected result, respondents were less likely to speak up to senior doctors. Lover expressed likelihood of speaking up was linked to younger age, male gender, being nurse and working on ward.

Respondents stated that they had experienced shortcuts, missing competencies, disrespect and performance problem. Majority of the respondents highlighted the observed concerns undermined patient safety, caused harm on patient, or led healthcare providers to consider leaving from their current positions. Few respondents indicated positions. Few respondents indicated
that they had discussing their concerns while most of respondents indicated that many of their concerns remained unaddressed. Respondents also reported that when the patients were put on the risk by other colleagues, they experienced lack of listening and responsiveness. Speaking up is a responsiveness. Speaking up is dependent. It is affected by multiple things such as person, group, organization, human factors and leadership.

sitive culture of safety in healthcare organization, peer to

peer accountability and speaking up were at desired level. However, if culture of safety was negative which means that it involves punitive actions and blames then nurses were less likely to speak up in the team. Nurses were 
Table 1 Summary of studies (Continued)

Martinez W., Etchegaray J.M. Thomas E.J., Hickson G.B.

Lehmann L.S., Schleyer A.M Best J.A., Shelburne J.T., May N.B., Bell S.K. (2015)

n: 136 (surgeons, anesthesiologists and nurses) more likely to not speak up towards managers, physicians, and more senio staff that they have more experience than them.

Speaking up' about patient safety concerns and

unprofessional behaviour among residents: validation of two scales

Surgical resident education in patient safety: where can we improve?

Study provided two scales that they are "speaking up climates patient safety concerns (SUC-Safe)" and

"speaking up climates unprofessiona behaviour (SUC-Prof). Scales help to measure safety and teamwork climate, assess degree of a culture that encourages speaking up about safety and professionalism concerns identify educational needs and track the progress in relevant interventions." Study results indicated that: 1) SUC for safety and SUC for professionalism were different from each other. 2) Providing prior formal training about patient safety was linked with more positive perceptions of speaking up climates for safety, not for professionalism. 3) Compared to males, female respondents were more likely to have negative perceptions of SUC for professionalism.

Three safety domains (Safety Culture Teamwork and Speaking Up) were scored higher among perioperative staff than surgical staff however it was found significant just for safety culture. Compared with surgery residents, surgery faculty scored higher in safety culture and speaking up. Respondents scored lowest for I feel free to question the decisio or action of those with more authority"(30\%). Senior respondents scored lower than juniors in the speaking up however it was not statistically significant $(p>0.05)$. Compared with direct care providers (preoperative, circulating, scrub and postoperative nurses), surgical and anesthesia faculties scored lower in the speaking up although, these differences were not significant $(p=0.32)$ 
Table 1 Summary of studies (Continued)

[36] Lukewich J., Edge D.S., Tranmer J,

Raymond J., Miron J., Ginsburg L

VanDenKerkhof E. (2015)

[41]

Kent L., Anderson G., Ciocca R. Shanks L., Enlow M., (2015)

Cohort

US

Hemingway W.M., O'Malley C., Silvestri S. (2015)

Nancy Y.J., Ryan D., Scott M.C. Daniele B., Katerune O., (2014)

n:714 nursing students

al Canada

nursing students' self-reported

confidence in learning about

patient safety in the classroom

and clinical settings: an annual

cross-sectional study

(2010-2013)

Effects of a senior practicum course on nursing students confidence in speaking up

for patient safety

n: 90 (RNs, Surgical

Safety Culture and Care: A Program to Prevent Surgical Errors Bayya J., Gillett B., Onoriode H. Weedon J., Altshuler L. Fisher N. (2014)

n:55 (encouraged $(n=28)$ or discouraged ( $n=27$ ) groups)

Ryan P.J., Hammond C., (2014)
Communication and psychological safety in veterans health administration work

environments

n: 641 interviews

Influence of surgeon behavio on trainee willingness to speak up: a randomized controlled trial

A Crew Resource Management Program Tailored to Trauma Resuscitation Improves Team Behavior and Communication
Majority of the nursing students didn't feel comfortable to speak up when safety events occur.

After senior practicum course applied to student, their confidence increased significantly however students' confidences in questioning someone of authority were not found statistically significant.

There was $54 \%$ increase in respondents that they would speak up if they are experiencing safety events.

Interviewees indicated that they felt safer to speak up in a psychologically safe work environment. Shared workmates norms and values about speaking norms and values about speaking up affected willingness to speak up
in the organization. So that, not just in the organization. So that, not just also coworker relationship plays important role for building psychological safe environment to speak up. Lack of organization to speak up Lack of organizational with unsafe psychological workplace. with unsafe psychological workplace. surgeon's behaviors can encourage surgeon's behaviors can encourage
or discourage medical students to or discourage medical students
speak up when there is a safety speak up when there is a safety
event. The results indicated that encouraged group were more likely to speak up than discouraged group. (82\% vs $30 \%$ and $p<0.001)$. The senior surgeons plays an essential role to improve and enhance patient safety and intraoperative communication at OR.

After Crew Resource Management (CRM) training applied to employees, results showed that healthcare staff were more likely to speak up when they have concern about safety. $(p<0.002)$ 
Table 1 Summary of studies (Continued)

[23] Schwappach D.L., Gehring K., (2014)

Schwappach D.L. Gehring K., (2014)
Cross Sectional Switzerland

n. 39 (32 physicians and 7 nurses at oncology unit)

Cross Sectional Switzerland n: 32 Saying it without words': a staff's experiences with speaking up about safety concerns

eaking up for patient safety by hospital-based health care professionals: a literature review of oncology sta to speak up about safety concerns
Damaging relationship with coworker was one of the barrier to speak up. Speaking up with wellknown co-worker was relatively easier than speaking to other professionals. Lack of interpersonal relationships among professionals increased risks and potential cost of not speaking up. Respondents also concerned about speaking up while patient was present in same place. $1 / 3$ of the interviewees thought that it caused lose in trust of the patient. Presence of other persons, knowledge gap, hierarchy, limited time and fears of speaking up were highlighted as barriers to speak up among the staff.

Professionals often used non-verbal communication when the safety events occurred. Speaking up was strongly linked to safety problems. Being silence associated with issues Being silence associated with issues such as hygiene, isolation and
invasive procedures. There was a invasive procedures. There was
culture and desire to speak up however "how" is remained due to hierarchicy.

There were some factors that influencing speaking up in healthcare organization. These were motivation to speak up, contextual factors (organizational support,

interdisciplinary policy making, teamwork, interpersonal relationships and attitude of leaders), individual factors (satisfaction, responsibility, confidence, communication skill and educational background), the perceived efficacy of speaking up, the perceived safety of speaking up (having fear), tactics and targets.

$57 \%$ of respondents indicated that they worked together as a team with their District Health Board. $70 \%$ of professionals agreed that they involved patients for improving their care. $69 \%$ of respondents indicated that it was easy for them indicated that it was easy for the
to speak up if they experience a perspectives on qualt safety in New Zealand public hospitals: findings from a national survey 
Table 1 Summary of studies (Continued) Dovey S., (2013)

Bowman C., Neeman N., Sehgal N.L., (2013)

safety event. The study found that there was an association between perceptions of stronger leadership and performances about three questions and survey items.

"Excuse me:" teaching interns Knowledge of the interns increased to speak up

significantly due to training program. There was an evidence to support shift in attitudes towards intended direction related to need for speaking up to seniors. There was not an effect of training on behaviors of interns.

Panel Report New (structured two Zealand round survey)

n: 11 internationally recognized experts on patient safety

Cross Sectional US

n: 121 medical students
(2013)

Lee H.M., (2013)
Enculturation of unsafe attitudes and behaviors: student perceptions of safety culture
What attributes of patients affect their involvement in safety? A key opinion leaders' perspective

There were 13 attributes that

essential for patients who would

like to maximize safer care. They

were found as: autonomy, awareness, conscientiousness, knowledge, rationality, responsiveness and vigilance. For instance, autonomy involves the ability to speak up, freedom to act independently.

Teamwork' and 'Organizational Learning' were rated highest while 'communication openness' and 'non-punitive response to error 'were rated lowest among the students. $56 \%$ of the medical student indicated that they would not speak up if they witness to a not speak up if they withess to a safety event. $55 \%$ of the respondents were afraid of asking questions related to safety events. $48 \%$ of the students felt that safety events were held against them. Medical students indicated desire to increase additional training regarding to patient safety.

Patient safety in spine surgery: regarding the wrong-site surgery
In order to promote safety culture at $O R$, the surgeons need to set

up horizontal communication (eliminate hierarchicy) and enable all team members to speak up in existence of a safety concern. Creating safety

culture that promotes speaking up

is important. All team members must feel free to speak up when safety event was recognized by them. 
Table 1 Summary of studies (Continued)

[11] Lyndon A., Sexton J.B.,

Simpson K.R., Rosenstein A.,

Lee K.A., Wachter R.M. (2013)

Cross Sectional US

n:33 interviews (nurses)

Speaking up, being heard: registered nurses' perception of workplace communication

Entwistle V.A., McCaughan D.,

Watt I.S., Birks Y., Hall J., Peat M.,

Williams B., Wright J., (2010)

Speaking up about safety concerns: multi-setting qualitative study of patients' views and experiences

Speaking up in case management, part II: implementing speaking up behaviors

Speaking up in case management, part l: ethical and professional considerations
Likelihood of speaking up while controlling bravery and assertiveness linked to higher perception of has respondent role, specialty experience and site. Compared to nurses, common potential harm was rated lower by physicians. $12 \%$ of the professionals were unlikely to speak up even if they perceived high potential harm.

Three domains were found that they played an important role in speaking up. These were 'influences' where organizational (peers, managers and administration) and individual things (cultural background, values, how they were raised, language and they were raised, language and an effect on nurses to speak up, 'message transmission' how safety relevant message was delivered and received and 'outcomes' about what were results of speaking up? Were there changes and feedbacks?

Ability to speak up depended on some evaluations such as workloads, priorities, relative importance of staff concerns, confidence about reasoning concerns, confidence about reason
for relevant concern, roles, responsibilities, likely consequences of speaking up and gravity of threat of harm. There were diverse results of speaking up. Healthcare staff were sometimes averted harm or provided welcome while sometimes made anxieties which ended up with potential harm on patient.

Healthcare staff often remain silent due to fear of unhealthy relations with their peers. In order to enable with their peers. In order to enab
healthcare staff to speak up, organizations and employees should recognize the value of speaking up mutually.

Fear of retaliation or organizational nonresponsiveness make "speaking up" often difficult. Ethical responsibility of case managers are ensuring their clients' health 
Table 1 Summary of studies (Continued) Minehart R.D., Podraza M. Rudolph J., Walzer T.

Raemer D. (2009)
Analyzed 97 wrong site surgery cases

Improving Patient Safety in Radiology: Concepts for a Comprehensive Patient Safety Program

Would you speak up if the consultant got it wrong? .. and would you listen if someone said you'd got it wrong? misses and actual occurrences

Teaching residents the twochallenge rule: a simulationbased approach to improve education and patient safety

Role of medical students in preventing patient harm and enhancing patient safety

Patients encouraged to "Speak Up"

An educational intervention to increase "speaking-up"
Wrong site surgery near

and welfare rather than their professional self-interests.

Creating a safety culture where professionals expected and encouraged to speak up is one of the components of culture transformation in healthcare organization.

The article suggested healthcare professionals to reflect around human error, teamwork, persona responsibilities about safety and non-technical skills (for example: speaking up).

Two of importance of teamwork and leadership aspects were empowering professionals to acknowledge concerns and speak up.

Usage of the two-challenge rule and advocacy-inquiry which improved residents' "speaking up" increased after debriefing. Frequency and quality of challenges towards doctors improved while there was no change for nurses.

Medical students may be good opportunity to prevent safety events and ensure safety in health care organizations. Cultural changes for patient safety were needed to increase proactive contribution of medical student.

Proactive patients were associated with better safety outcomes. Patient involvement and participating to decision making process were found as ways to reduce occurrence of medical events. behaviors in nurses and improve patient safety
Study results showed that, registered nurses in intervention arm had a significant difference in 'mean speaking up scores' from baseline to posttest $(p<0.0001)$ while control group was having no control group was having no was a statistically significant differences in mean scores on the 'list of individual nurse behaviors 
Table 1 Summary of studies (Continued)

Heyrani A., (2015)

for intervention group $(p=0.0015)$ while there was no significant differences in control arm $(p=0.27)$

Training nurses regarding to speaking up can increase their perceptions of ability to improve safety and speak up.

Speaking up: factors and issues Literature review showed that abilities in nurses advocating for patients to speak up may be depend on when patients are in jeopardy

organizational culture, leadership support, communication style, oppression, power and culture. Theoretical framework on speaking up was illustrated in the study.

The culture of patient safety in an Iranian intensive care unit

Lack of speaking up' was found as a one of the safety challenges.

n: 59 (16 patients, 4 patients' Seeing it from both sides: do relatives, 39 healthcare staff) approaches to involving patients in improving their safety risk damaging the trust between patients and healthcare professionals? An interview study

Overall, positive results were founded however patients thought that speaking up might result with

unintended consequences. Speaking up might appear rude or disrespectful, makes staff upset and endanger their care. Healthcare staff were found that they were welcoming patient's questions. Providers thought that if patients asked many questions and wrote something,

they probably will complain about them.

Patient-mediated approaches which prompt patients to speak up criticized by professionals due to rarely considering the needs of healthcare staff.

Deafening silence? Time to reconsider whether organizations are silent or deaf when things go wrong

Focusing just for organization silence is a mistake due to misrepresenting safety events and complexities of safety culture. In order to find solutions, study suggested to focus on why healthcare organizations are deaf and disregard to staff concerns. Influencing and promoting for better culture of speaking up better culture of speaking up exist in such systems where there are better listening and valuing of provider concerns. Healthcare staff safety events and expect to receive 
Table 1 Summary of studies (Continued)

Etchegaray J.M., L L L H:42 studies Thomas E.J., (2015)

Liao J.M., Thomas E.J., Bell S.K., (2014) feedback (action taken or reasons for not acting).

Back to basics: preventing surgical site infections

Surgical site infection can be avoided

via speaking up when sterile technique was broken by colleagues.

Accountability to others and

empowerment to speak up

were found essential for improving quality of healthcare.

Engaging Employees: The The High-Performance Work Systems Importance of High-Performance survey (HPWSs) was found as a Work Systems for Patient Safety strongest predictor of extent to which healthcare practitioners felt confident to speak up about safety events.

Speaking up about the dangers of the hidden curriculum

Learning environment was shaped by individual decision to speak up or remain silent, promoting unprofessional behavior or following up better alternatives. Progress in creating safety culture with consideration of those things may enable students, residents, faculty and patients to speak up about safety event.

$n=64$ (11 physicians, $12 \quad$ Practice and quality imaging fellows or residents, improvement: successful 19 nurses and 5 technologist or administrative staff) tools into an academic interventional ultrasound Speaking up' was one of the most respondent

part of the study. After
implementation of Team Strategie and Tools to Enhance Performance and Patient Safety (TeamSTEPPS) participants rated lower for "In this clinical area, it is difficult to speak up if I perceive a problem with pation if / percelve a problem with patient care (before implementation $69.4 \%$ of agreement, after implementation $25.5 \%$ agreement, $p<0.001$ )

What Would I Want For My Changing OR safety culture to where all members of team have a common understanding of patient patient's needs, operative plan and the goals can facilitate detection of safety issue. In a better safety culture, members are more likely to speak up when they experience safety event. 
Table 1 Summary of studies (Continued)

\begin{tabular}{|c|c|c|c|c|c|c|}
\hline [24] & $\begin{array}{l}\text { Raemer D.B., KolbeM., } \\
\text { Minehart RD, Rudolph J.W., } \\
\text { Pian-Smith M.C. (2015) }\end{array}$ & $\mathrm{RCT}$ & US & $\begin{array}{l}n=71 \text { [intervention ( } n=35) \\
\text { and control }(n=36) \text { groups] }\end{array}$ & $\begin{array}{l}\text { Improving Anesthesiologists' } \\
\text { Ability to Speak Up in the } \\
\text { Operating Room: A Randomized } \\
\text { Controlled Experiment of a } \\
\text { Simulation-Based Intervention } \\
\text { and a Qualitative Analysis of } \\
\text { Hurdles and Enablers }\end{array}$ & $\begin{array}{l}\text { There was no statistically significant } \\
\text { differences between intervention } \\
\text { and control groups regarding to } \\
\text { respect to speaking up actions. } \\
\text { Uncertainty about the issue, } \\
\text { familiarity with the individual, } \\
\text { stereotypes of the others on the } \\
\text { team, respect for experience and } \\
\text { the repercussion expected were } \\
\text { found as the five most frequent } \\
\text { barriers to speak up. Having a } \\
\text { second opinion or getting help, } \\
\text { realizing the speaking up problem, } \\
\text { certainty about the consequences of } \\
\text { the speaking up and having a } \\
\text { speaking up rubric were found } \\
\text { as the five most frequent enablers } \\
\text { for speaking up. }\end{array}$ \\
\hline [74] & $\begin{array}{l}\text { Sur M.D., Schindler N., Singh P., } \\
\text { Angelos P., Langerman A., }\end{array}$ & Cross Sectional & US & $\begin{array}{l}n=18 \text { interviews (senior } \\
\text { residents across } 4 \text { surgical } \\
\text { subspecialties) }\end{array}$ & $\begin{array}{l}\text { Young surgeons on speaking } \\
\text { up: when and how surgical } \\
\text { trainees voice concerns about } \\
\text { supervisors' clinical decisions }\end{array}$ & $\begin{array}{l}\text { A tension between prioritizing } \\
\text { obligations to the patient and } \\
\text { conceding ultimate decision making } \\
\text { authority to supervisors were } \\
\text { highlighted by the participants. } \\
\text { There were factors that influencing } \\
\text { the willingness to voice concerns } \\
\text { such as supervisory (approachability), } \\
\text { systematically (culture of safety in } \\
\text { department, resident autonomy), } \\
\text { clinically (risk of harm, evidence } \\
\text { quality) and trainee (knowledge). } \\
\text { Most of the concerns were expressed } \\
\text { by the participants via using question } \\
\text { form while few of the participants } \\
\text { preferred to voice directly. }\end{array}$ \\
\hline [32] & $\begin{array}{l}\text { Rance S., McCourt C., Rayment J., } \\
\text { Mackintosh N., Carter W., } \\
\text { Watson K., Sandall J.(2013) }\end{array}$ & Cross Sectional & UK & $\begin{array}{l}n=58 \text { patients (postnatal } \\
\text { women) }\end{array}$ & $\begin{array}{l}\text { Women's safety alerts in } \\
\text { maternity care: is speaking } \\
\text { up enough? }\end{array}$ & $\begin{array}{l}\text { Half of the women indicated that } \\
\text { there were insistent and vehement } \\
\text { communication with staff while } \\
\text { experiencing failures. Interviewees } \\
\text { also highlighted receiving lack of } \\
\text { listening and responds from } \\
\text { professionals. } 14 \text { women thought } \\
\text { that they experienced urgent safety } \\
\text { issues. The patients thought that the } \\
\text { presence of their partners or relatives } \\
\text { encouraged them to speak up when } \\
\text { they have concerns. Distress and } \\
\text { harm were described by the several } \\
\text { women when the professionals failed } \\
\text { to listen them. }\end{array}$ \\
\hline
\end{tabular}


Table 1 Summary of studies (Continued)

\begin{tabular}{|c|c|c|c|c|c|c|}
\hline [33] & $\begin{array}{l}\text { Rainey H., Ehrich K., } \\
\text { Mackintosh N., Sandall J. } \\
(2015)\end{array}$ & Cross Sectional & UK & $\begin{array}{l}n=20 \text { interviews ( } 13 \text { patients } \\
\text { and } 7 \text { relatives) }\end{array}$ & $\begin{array}{l}\text { The role of patients and their } \\
\text { relatives in 'speaking up' about } \\
\text { their own safety - a qualitative } \\
\text { study of acute illness }\end{array}$ & $\begin{array}{l}\text { Raising concerns from patients and } \\
\text { their relatives were depend on their } \\
\text { ability to recognize changes in } \\
\text { 'self-monitoring', 'culture and system } \\
\text { of health care', 'clinical condition' and } \\
\text { 'confidence and trust'. Healthcare staff } \\
\text { displayed a role of mediator when } \\
\text { there were concerns from patients } \\
\text { and their relatives. }\end{array}$ \\
\hline [75] & $\begin{array}{l}\text { Rabøl L.I., Andersen M.L., } \\
\text { Ostergaard D., Bjørn B., Lilja B., } \\
\text { Mogensen T. (2011) }\end{array}$ & Cross Sectional & Denmark & $\begin{array}{l}n=84 \text { root cause analyses } \\
\text { reports (RCAR) of six hospitals }\end{array}$ & $\begin{array}{l}\text { Republished error } \\
\text { management: Descriptions } \\
\text { of verbal communication } \\
\text { errors between staff. An } \\
\text { analysis of } 84 \text { root cause } \\
\text { analysis-reports from Danish } \\
\text { hospitals }\end{array}$ & $\begin{array}{l}\text { Verbal communication errors were } \\
\text { identified in } 44 \text { reports which } \\
\text { generated } 52 \% \text { of the total number } \\
\text { of the reports. 'Hesitance in speaking } \\
\text { up' was found in } 10 \text { reports which } \\
\text { generated } 23 \% \text { of the verbal } \\
\text { communication errors. }\end{array}$ \\
\hline$[76]$ & Beyea S.C., (2008) & Cross Sectional & US & $\mathrm{n} / \mathrm{a}$ & $\begin{array}{l}\text { Speaking up for quality and } \\
\text { patient safety }\end{array}$ & $\begin{array}{l}\text { Raising concerns requires to have } \\
\text { knowledge and understanding of } \\
\text { best practices and scientific rationale. } \\
\text { In order to advocate patient and serve } \\
\text { to him/her, professional require to take } \\
\text { a risk of voicing their concerns. } \\
\text { Holding each other as an accountable } \\
\text { or addressing safety events to peers } \\
\text { were the things that needed for } \\
\text { speaking up. }\end{array}$ \\
\hline
\end{tabular}


Factors that influencing speaking up

Factors that influencing speaking up among professional

There were bunch of studies that they illustrated influencing factors of speaking up in healthcare organization. The one which was introduced by Marrison EW had better classification of the factors that influencing healthcare staff's speaking up behaviors (Fig. 3). Perceived efficacy of speaking up, motivation and clinical factors, individual factors, general contextual factors and perceived safety of speaking up were found as categorized influencing factors of speaking up [18].

\section{Perceived efficacy of speaking up}

Studies illustrated that healthcare staff expect to be informed about safety issues that happen in their unit. They should feel that management is not sweeping the issues under the rug (nothing will be done) [19-21]. Impact of work and perception of autonomy are considered under the personal control which influence speaking up behaviors [20].

\section{Motivation and clinical factors}

Predictors of the decision to speaking up have multiple influential factors such as: limited time, cumbersome documentation systems, clinical frame, lack of managerial support or follow up for an event, the level of perceived potential harm (varied perception in harm rating) and clinical situation (clarity, ambiguity, contrast) $[19,20,22,23]$.

\section{Individual factors}

Individual factors that influencing speaking up are illustrated on Fig. 4 (Fig. 4). Speaking up is varied towards well-known coworker and unknown person [23, 24]. Lover expressed likelihood of speaking up is linked to younger age, male gender, being nurse and working on ward [22]. Compared to males, females are more likely to have negative perceptions of speaking up [25]. Persons who express their concerns positively are associated with better satisfaction and promote safer environment [20].

\section{General contextual factors}

There are several organizational and managerial factors that affect speaking up behaviors in healthcare organization and they are illustrated on Fig. 5 (Fig. 5). If culture of safety is negative which means that it involves punitive actions and blames then nurses are less likely to speak up in the team [26]. Visible and strong administrative support has been enhancing voicing behaviors of professionals. It has been found that professionals tend to speak up when hospital policies openly support and encourage them to raise their concerns [20].

\section{Perceived safety of speaking up}

Presence of an audience (such as fear of causing lose in trust of the patient), perceived response of addressed actor (colleague) (fear of appearing incompetent, concerns and reprisal), seniority of the actor and his/her role, existence of senior encouragement towards speaking up behaviors, existence of common understanding of patient and patient needs,

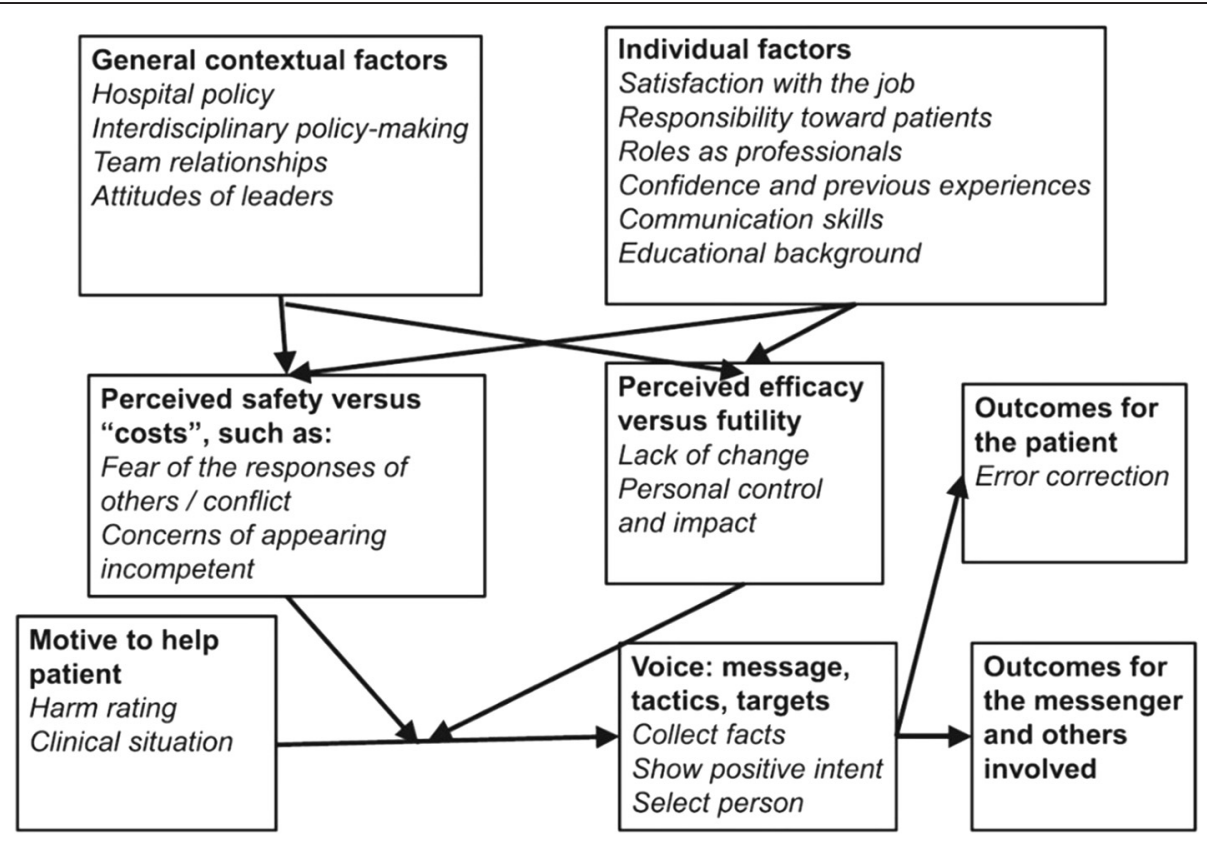

Fig. 3 Framework of Marrison's model of employee speaking up 


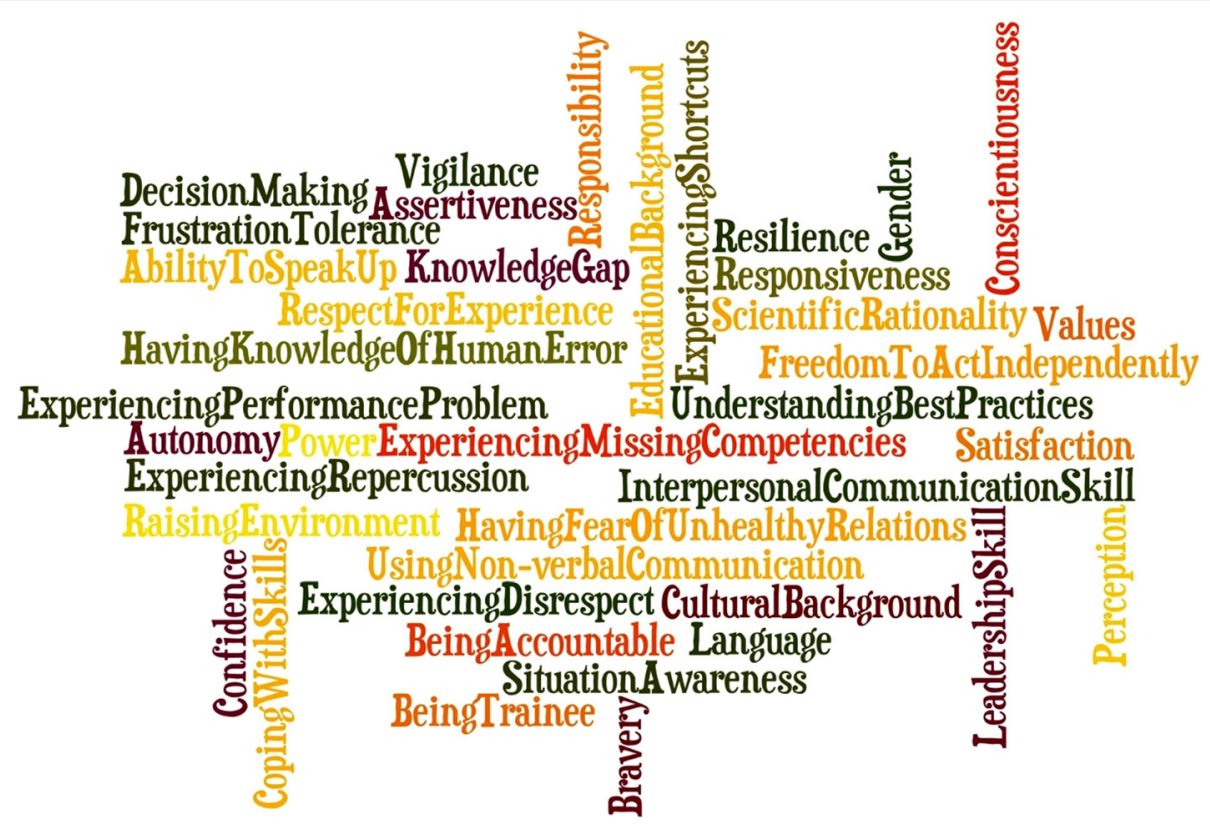

Fig. 4 Individual factors that influencing speaking up among Professional

uncertainty about the issue, actual or perceived punishment towards the employee reporting an event and the fear, cost and results of raising concerns are found influencing factors about remaining silent or speaking up [11, 19, 22-24, 27-29]. Likelihood of speaking up is strongly influenced by seniority of the actor. Speaking up is significantly higher among managerial staff. Compared to senior staff, junior staff have two times discomfort about speaking up [22].

Factors that influencing speaking up among patients Four studies were identified that they studied patient voicing up behaviors and patient safety. Proactive patients are associated with better safety outcomes. Patient involvement, participating to decision making process are ways to reduce occurrence of medical events [30]. Sometimes, if patient speaks up, it might result with unintended consequences. Speaking up might appear rude or disrespectful, makes staff upset and endanger patient care. Healthcare staff are welcoming patient's questions. Providers thought that if patients ask many questions and wrote something, they probably will complain about them. Patient-mediated approaches which prompt patients to speak up are criticized by professionals due to rarely considering the needs of healthcare staff [31]. In another study, half of the patients in maternity care indicated that there were insistent and vehement communication with staff while experiencing failures. Interviewees also highlighted receiving lack of listening and responds from professionals. 14 women thought that they experienced urgent safety issues. The patients think that the presence of their partners or relatives encourage them to speak up when they have concerns. Distress and harm are described by patients when the professionals failed to listen them [32]. 
Raising concerns from patients and their relatives are depend on their ability to recognize changes in 'selfmonitoring,' 'culture and system of health care', 'clinical condition' and 'confidence and trust'. Healthcare staff display a role of mediator when there are concerns from patients and their relatives [33].

\section{Effectiveness of speaking up for patient safety}

There are several studies that clearly demonstrate relationship between speaking up behaviors and patient safety. A randomized control study (RCT) aimed to identify how surgeon's behaviors can encourage or discourage medical students to speak up when there is a safety event. The results indicated that encouraged group were more likely to speak up than discouraged group ( $82 \%$ vs $30 \%$ and $p<0.001$ ). The senior surgeons play an essential role to improve and enhance 'patient safety' and 'intraoperative communication' at Operating Theatre [28]. In another RCT, Non- technical skills coaching improved in the intervention group compared to those in control group (p: 0.04). Intervention group was faster to respond unstoppable bleeding ( $\mathrm{p}:$ 0.03) [34].

Speaking up is strongly linked to safety problems. Being silence is associated with issues such as hygiene, isolation and invasive procedures [35].

\section{Effectiveness of speaking up training}

It has been found that nursing students don't feel comfortable to speak up when safety events occur [36, 37]. Providing prior formal training about patient safety is linked with more positive perceptions of speaking up climates for safety [25]. In a case control study, nurses were trained regarding to speaking up behaviors. Results showed that their perceptions of ability to improve safety and speak up behaviors increased. Intervention arm had a significant difference in 'mean speaking up scores' from baseline to posttest $(p<0.0001)$ while control group was having no significant change $(p=0.68)$ [38]. In a cohort study, knowledge of the interns increased significantly due to training program. There was an evidence to support a shift in attitudes towards intended direction related to need for speaking up to seniors however, there was not an effect of training on behaviors of interns [39]. In another cohort study, after Crew Resource Management (CRM) training applied to employees, results showed that healthcare staff were more likely to speak up when they have concern about safety $(p<0.002)$ [40]. In another cohort study, after senior practicum course applied to student, their confidence increased significantly however students' confidences in questioning someone of authority was not found statistically significant [41]. After successful implementation of TeamSTEPPS tools in one of the cohort study, participants rated lower for "In this clinical area, it is difficult to speak up if I perceive a problem with patient care" (before implementation $69.4 \%$ of agreement, after implementation $25.5 \%$ agreement, $p<0.001$ ) [42].

In some studies, medical students indicated desire to increase additional training regarding to patient safety [37]. They (medical students) may be good opportunity to prevent safety events and ensure safety in health care organizations. Cultural changes in patient safety are needed to increase proactive contribution of medical student when they experience safety events [43]. Studies have been showing that there is a continued need for communication, additional education, medication safety and prioritization in practice $[19,37]$. So that, providing training in regular intervals may improve speaking up behaviors of both medical students and residents of hospital.

\section{Discussion}

Speaking up is responsibility of everyone in the team. It is not essential just for operating theatre but also applicable to any other relevant situations in health setting. It is obviously needed when staff and patient are at risk or vulnerable, and when the team members have lack of awareness. Speaking up is an essential action considered belong professional accountability [44]. Some enabler of speaking up could be as follows:

- In a result of a RCT, having a second opinion or getting help, realizing the speaking up problem, certainty about the consequences of the speaking up and having a speaking up rubric were found as the five most frequent enablers for speaking up [24].

- Recommendation of Institute for Healthcare Improvement (IHI): In order to speak up in healthcare organization [21]: Psychologically safe environment is needed for speaking up openly. Active leadership and management support are important to talk about concerns confidently. Transparency that where healthcare team and management are handling safety issues seriously rather that sweeping them under the rug. Fairness that where people are not receiving punishment or blame due to system based errors.

- As an individual level, 'identifying and reporting problems with procedures and policies', 'reporting unsafe working conditions, adverse events and close calls' and speaking up when having concerns [45].

- Using structured techniques to communicate effectively (for instance: using SBAR, critical language) [45].

- Having knowledge of human factors [46, 47].

- Studies have been showing that there is a continued need for communication, additional education, medication safety and prioritization in practice 
$[19,37]$. So that, providing training regarding to critical behaviors in regular intervals may improve speaking up behaviors of both medical students and residents of hospital.

- Ensuring 'Safety Culture' and 'Horizontal Communication' in a dynamic clinical setting $[27,46,48]$.

- Creating 'shared workmates norms', 'common understanding of patient and patient's needs' and 'values about speaking up' may promote willingness to speak up in an organization [29, 48, 49].

- Strong leadership and supervisory [50].

- Listening and valuing of provider concerns [51].

- Patient involvement and participating to decision making process [30].

In the relevant literature, theoretical framework on speaking up (illustrated for better understanding by Jennifer Rainer) and relationship between employees' voice concerns and organizational outcomes (illustrated for better understanding by Aled Jones and Daniel Kelly) are illustrated in (Fig. 6 and Fig. 7). In this literature review, various influencing factors of speaking up are listed via using Marrison's model of employee voice (Fig. 3). The decision to speak up in a clinical setting is dynamic, highly context-dependent, embedded in the interaction rituals that suffuse everyday work and constrained by organizational dynamics in healthcare [27, 46]. Voicing is affected by multiple things such as person, group, organization, human factors and leadership [46].
Settlement of positive safety culture in healthcare organization is an important action that promote mutual trust among professionals. Culture of safety encourage healthcare staff to talk freely about unsafe events and their management without fear of stigmatization, blame or punishment. For improvement in speaking up behaviors among health care organization, leaders may require to take varied action plans regarding to need and level of 'speaking up behaviors' and 'safety culture'. The need for critical behaviors of safety may vary in healthcare organizations. In order to have desired level of behavioral results for enhancing patient safety, varied tools can be used by leaders to assess current level of 'speaking up behaviors' and 'culture of safety'. Those tools are:

- Hospital Survey on Patient Safety Culture, The Agency for Healthcare Research and Quality (AHRQ) [52].

- Two scales that they are "speaking up climates patient safety concerns (SUC-Safe)" and "speaking up climates unprofessional behavior (SUC-Prof). Scales help to measure safety and teamwork climate, assess degree of culture that encourages speaking up about safety and professionalism concerns, identify educational needs and track the progress in relevant interventions [25].

- The Safety Attitudes questionnaire (SAQ), The Agency for Healthcare Research and Quality (AHRQ) [53].

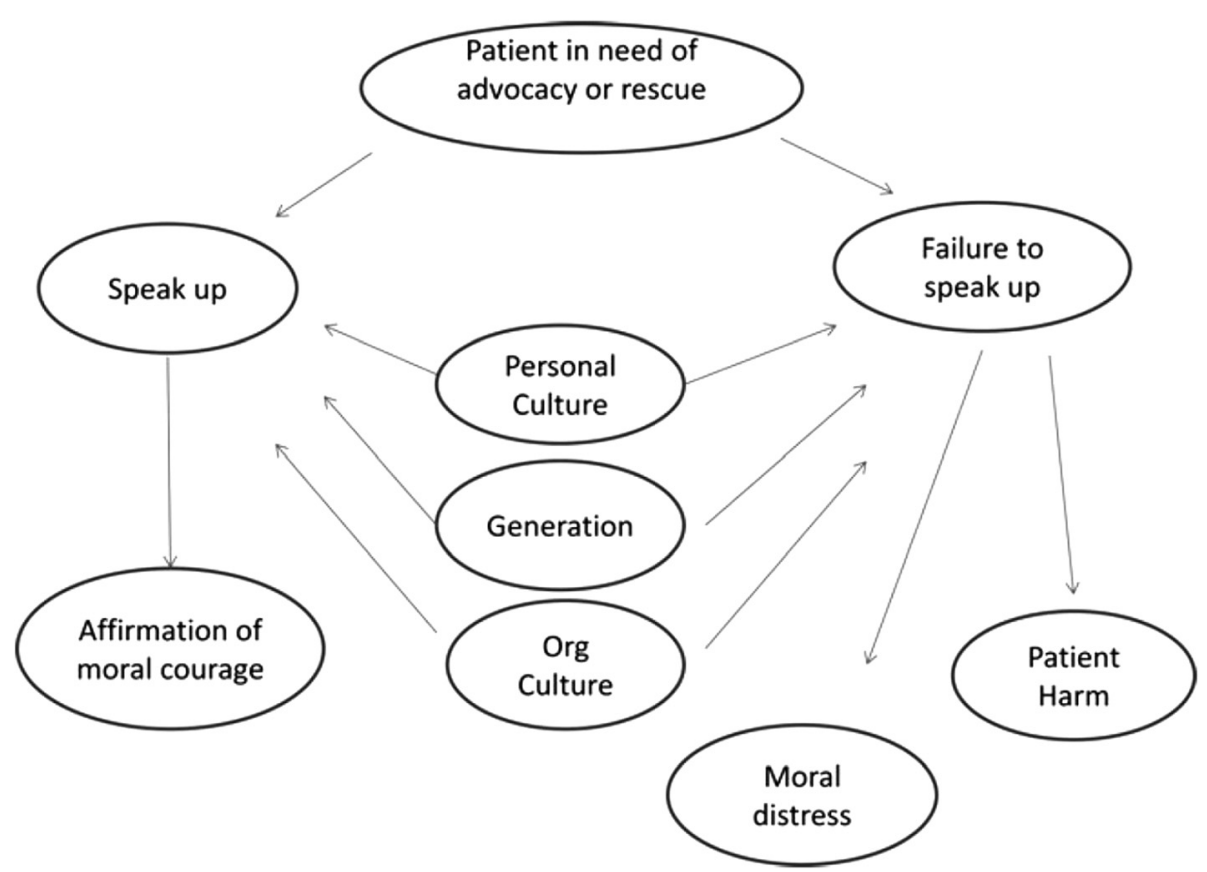

Fig. 6 Theoretical framework on speaking up. Reprinted and copyright by permission of Jennifer Rainer, January 11, 2016 


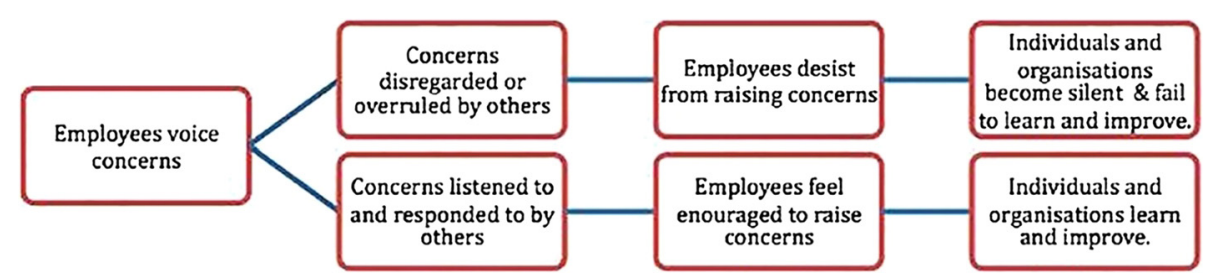

Fig. 7 Relationship between employees' voice concerns and organizational outcomes. Reprinted and copyright by permission of Aled Jones and Daniel Kelly, January 11, 2016

- The High-Performance Work Systems survey (HPWSs) was found as a strongest predictor of extent to which healthcare practitioners felt confident to speak up about safety events [54].

- Social science and Organization behavior research (OBR) help health care organization to create safer environment in their units/services. They are helping health organizations to shift from slow improvement to faster and more effective progressivity in safety culture [55].

This study was first study about not just identifying factors that influencing speaking up behaviors among providers but also including factors of patients' voicing up behaviors for safety. This study is also providing some 'enablers of speaking up behaviors' which may help leaders and professionals' decision making process for quality and safety improvements in their organizations.

\section{Limitation}

Most of the studies were cross sectional and studied influencing factors of speaking up behaviors. Further experimental studies are needed for identifying enabling factors of speaking up behavior for enhancing and improving patient safety. On the other hand, most of the relevant studies were conducted in western countries, so that influencing factors may vary for eastern countries. Before taking any decision or having implementations about safety, relevant tools which mentioned in introduction part of this study are suggested for identifying local influencing factors of speaking up behaviors.

\section{Conclusion}

Speaking up is one of the critical behaviors of patient safety [10]. Awareness of factors that 'influencing' and 'enabling' speaking up behaviors may help leaders and decision makers to improve quality and safety of healthcare in their organization. This study is providing complex process of speaking up behavior and their impacts on patient safety outcomes.

\section{Acknowledgements}

The author would like to express his most sincere gratitude to his supervisor, Dr. Janice Mary Johnston who not only guided and advised him, but also provided him with thoughtful comments while writing his project. Also, he would like to thank the current chairperson at Committee on Quality and Safety, HAHO, HKSAR, Dr. Hing Yu So who advised him and kindly answered his relevant questions during preparation of his project.

Lastly, the author wish to acknowledge his family, local and non-local friends and his school's staff for their everlasting support and encouragements while studying at School of Public Health the University of Hong Kong.

\section{Funding}

This review received no specific grant from any funding agency in the public, commercial, or not-for-profit sectors.

\section{Availability of data and materials}

53 relevant articles were identified in 83 articles. Those 53 articles consist of 4 literature reviews, 3 RCTs, 8 cohorts, 1 case control, 34 cross sectional studies and 3 reports. The author of this study agrees to make the raw data and materials described in his manuscript freely available to any scientist wishing to use them for non-commercial purposes, as long as this does not breach participant confidentiality. All the datasets on which the conclusions of this study's manuscript rely freely available to all readers of this manuscript. The article is universally and freely accessible via the Internet, in an easily readable format. All publications are deposited immediately upon publication, without embargo, in an agreed format - current preference is XML with a declared DTD - in at least one widely and internationally recognized open access repository. The author or copyright owner (s) irrevocably grant (s) to any third party, in advance and in perpetuity, the right to use, reproduce or disseminate the article/book in its entirety or in part, in any format or medium, provided that no substantive errors are introduced in the process, proper attribution of authorship and correct citation details are given, and that the bibliographic details are not changed.

\section{Competing interests}

The author of this study declares that the Project and the review work thereof represent his own work, except where due acknowledgement is made, and that it has not been previously included in a thesis, dissertation or report submitted to this University or to any other institution for a degree, diploma or other qualifications.

The author have completed the ICMJE uniform disclosure form at www.icmje.org/coi_disclosure.pdf and declare: no support from any organisation for the submitted work; no financial relationships with any organisations that might have an interest in the submitted work in the previous years; no other relationships or activities that could appear to have influenced the submitted work.

\section{Consent for publication}

Not applicable.

\section{Ethics approval and consent to participate}

Ethics approval of this literature review was obtained from Research Ethics Committee of The University of Hong Kong.

Received: 31 May 2016 Accepted: 1 August 2016

Published online: 19 August 2016

References

1. Lesson 1 The Definition (s) of Quality, Department of Management \& Marketing, Sam Houston State University. Retrieved on October 25, 2015 from http://www.shsu.edu/ mgt_ves/mgt481/lesson1/lesson1.htm. 
2. Harris MG. Managing Health Services: Concepts and Practice, 2006. chapter 16, p 393

3. Crossing the Quality Chasm. A New Health System for 21st Century. Institute of Medicine. 2011.

4. World Health Organization. Patient safety. 2013. Retrieved from website: http://www.who.int/patientsafety/about/en/.

5. Quality and Risk Management Annual Report 2012-2013, Hospital Authority, Hong Kong SAR. P:15

6. To Err Is Human: Building a Safer Health System. Institute of Medicine Nov, 2011. Retrieved on July 13, 2015 from http://iom.nationalacademies.org/ / media/Files/Report\%20Files/1999/To-Err-is-Human/ To\%20Err\%20is\%20Human\%201999\%20\%20report\%20brief.pdf.

7. Reason J. Human Error. Cambridge: Cambridge University Press; 1990. http://www.ha.org.hk/haho/ho/psrm/COPYQRM201213.pdf.

8. World Health Organization, WHO Library Cataloguing-in-Publication Data. Who patient safety curriculum guide: multi-professional edition. (ISBN 978 924150195 8). 2011. Retrieved from website: http://whqlibdoc.who.int/ publications/2011/9789241501958_eng.pdf.

9. World Health Organization. WHO Patient Safety Curriculum Guide for Medical Schools. Geneva: World Health Organization; 2008.

10. Lesson 3, PS 100: Introduction to Patient Safety. Open School, Institute for Healthcare Improvement (IHI). Retrieved on October 26, 2015 from $\mid \mathrm{HI}$ available on http://app.ihi.org/Ims/lessondetailview. aspx?LessonGUID=0a152256-edd5-4edd-8e1af947a71f8f1e\&CourseGUID=c67a038c-b021-43c3-b7b8f74e4ec303f4\&CatalogGUID=6cb1 c614-884b-43ef-9abd-d90849f183d4.

11. Lyndon A, Sexton JB, Simpson KR, Rosenstein A, Lee KA, Wachter RM. Predictors of likelihood of speaking up about safety concerns in labour and delivery. 2013. Retrieved from PubMed database on December 16, 2015 available on http://www-ncbi-n/m-nih-gov.eproxy1.lib.hku.hk/pmc/articles/ PMC3264837/pdf/nihms314480.pdf.

12. Welcome. Patient Safety Institute (PSI). Retrieved on July 14, 2015 from http://www.ptsafety.org/whoweare/welcome.html.

13. Kaiser Family Foundation / Agency for Healthcare Research and Quality/ Harvard School of Public Health National Survey on Consumers' Experiences with Patient Safety and Quality Information, November 2004 (Conducted July 7 - September 5, 2004). Retrieved from: http:// kaiserfamilyfoundation.files.wordpress.com/2013/01/national-survey-onconsumers-experiences-with-patient-safety-and-quality-informationsurvey-summary-and-chartpack.pdf.

14. World Health Organization. 10 facts on patient safety. 2013. Retrieved from website: http://www.who.int/features/factfiles/patient_safety/patient_safety_ facts/en/index.html.

15. John Ovretveit, Achieving "value improvements" changes which improve quality and save money. The International Society for Quality in Health Care (ISQua). Retrieved on July 26, 2015 from http://www.isqua.org/docs/geneva2012-docs/john-ovretveit.pdf?sfvrsn =0

16. Marshall DA, Manus DA. AORN J. 2007:86:994-1011.

17. SQUIRE 2.0 Guidelines, Standards for Quality Improvement Reporting Excellence. Retrieved from SQUIRE website on July 24, 2016 available http://www.squirestatement.org/index.cfm?fuseaction $=$ page.viewpage\&pageid $=471$.

18. Marrison EW. Employee voice behavior: integration and directions for future research. Acad Manag Ann. 2011;5(1):373-412.

19. Ulrich B, Kear T. Patient Safety Culture in Nephrology Nurse Practice Settings: Initial Findings. 2015. Retrieved from PubMed database on December 8, 2015 available on http://www-ncbi-nlm-nih-gov.eproxy1.lib. hku.hk/pubmed/26295089

20. Okuyama A, Wagner C, Bijnen B.. Speaking up for patient safety by hospital-based health care professionals: a literature review. 2014. Retrieved from PubMed database on December 15, 2015 available on http://www-ncbi-n/m-nih-gov.eproxy1.lib.hku.hk/pmc/articles/ PMC4016383/pdf/1472-6963-14-61.pdf

21. Summary Sheet, Patient Safety 106: Introduction to Culture of Safety. Open School, Institute for Healthcare Improvement $(\mathrm{IHI})$. Retrieved on October 19, 2015 from IHI available on http://app.ihi.org/lms/lessondetailview. aspx?LessonGUID=4b250d37-cf44-4561-b83053ed5865c6b8\&CourseGUID=789d9cbb-7dd3-4fe9-8df2e0c63725b350\&CatalogGUID=4cc435f0-d43b-4381-84b8-899b35082938.

22. Schwappach DLB, Gehring K. Silence that can be dangerous: a vignette study to assess healthcare professionals' likelihood of speaking up about safety concerns. 2014. Retrieved from EBSCOhost database on December 8,
2015 available on http://web.a.ebscohost.com.eproxy2.lib.hku.hk/ehost/ pdfviewer/pdfviewer?sid=8aec3763-ba8b-4a39-b4ef-

197977e423d3\%40sessionmgr4001\&vid=16\&hid=4212

23. Schwappach DL, Gehring K. Trade-offs between voice and silence: a qualitative exploration of oncology staff's decisions to speak up about safety concerns. 2014. Retrieved from PubMed database on December 15, 2015 available on http://www-ncbi-nlm-nih-gov.eproxy2.lib.hku.hk/pmc/ articles/PMC4105519/pdf/1472-6963-14-303.pdf.

24. Raemer DB, KolbeM, Minehart RD, Rudolph JW, Pian-Smith MC. Improving Anesthesiologists' Ability to Speak Up in the Operating Room: A Randomized Controlled Experiment of a Simulation-Based Intervention and a Qualitative Analysis of Hurdles and Enablers. 2015. Retrieved from Ovid on December 29, 2015 available on http://ovidsp.tx.ovid.com.eproxy2.lib.hku.hk sp-3.21.0a/ovidweb.cgi?WebLinkFrameset=1\&S=JKPIFPHJNGDDGFHLN CIKGCIBBJPMAA00\&returnUrl=ovidweb.cgi\%3f\%26Full\%2bText\%3dL\%257cS. sh.22.23\%257c0\%257c00001888-201604000-00030\%265\%3dJKPIFPHJNGD DGFHLNCIKGCIBBJPMAA00\&directlink=http\%3a\%2f\%2fovidsp.tx.ovid.com \%2fovftpdfs\%2fFPDDNCIBGCHLNG00\%2ffs046\%2fovft\%2flive\%2fgv023\%2f0 0001888\%2f00001888-201604000-00030.pdf\&filename=Improving +Anesthesiologists\%27+Ability+to+Speak+Up+in+the+Operating +Room\%3a++A+Randomized+Controlled+Experiment+of+a+SimulationBased+Intervention+and+a+Qualitative+Analysis+of+Hurdles+and+Enablers \&pdf_key=FPDDNCIBGCHLNG00\&pdf_index=/fs046/ovft/live/gv023/ 00001888/00001888-201604000-00030.

25. Martinez W, Etchegaray JM, Thomas EJ, Hickson GB, Lehmann LS, Schleyer AM, Best JA, Shelburne JT, May NB, Bell SK. 'Speaking up' about patient safety concerns and unprofessional behaviour among residents: validation of two scales. 2015. Retrieved from Quality and Safety BMJ on December 9, 2015 available on http://qualitysafety.bmj.com.eproxy1.lib.hku.hk/content/ 24/11/671.full.pdf+html.

26. Jansen Lockett J, Barkley L, Stichler J, Palomo J, Kik B, Walker C, Donnelly J, Willon J, Sanborn J, O'Byrne N. Defining Peer-to-Peer Accountability From the Nurse's Perspective. 2015. Retrieved from Ovid database on December 9, 2015 available on http://ovidsp.tx.ovid.com.eproxy2.lib.hku.hk/sp-3.21.0a/ ovidweb.cgi?WebLinkFrameset=1\&S=FDHNFPFJHHDDGFLKNCIKMBFBIKL DAA00\&returnUrl=ovidweb.cgi\%3f\%26Full\%2bText\%3dL\%257cS.sh.22. 23\%257c0\%257c00005110-201511000-00009\%26S\%3dFDHNFPFJHHD DGFLKNCIKMBFBIKLDAA00\&directlink=http\%3a\%2f\%2fovidsp.tx.ovid.com \%2fovftpdfs\%2fFPDDNCFBMBLKHH00\%2ffs046\%2fovft\%2flive\%2fgv023\% 2f00005110\%2f00005110-201511000-00009.pdf\&filename=Defining+Peer-toPeer+Accountability+From+the+Nurse\%27s+Perspective.\&pdf_ key=FPDDNCFBMBLKHH00\&pdf_index=/fs046/ovft/live/gv023/00005110/ 00005110-201511000-00009.

27. Szymczak JE. Infections and interaction rituals in the organisation: Clinician accounts of speaking up or remaining silent in the face of threats to patient safety. 2015. Division of Infectious Diseases and The Center for Pediatric Clinical Effectiveness, The Children's Hospital of Philadelphia, USA. Retrieved from PubMed database on November 23, 2015 available on http://wwwncbi-nlm-nih-gov.eproxy2.lib.hku.hk/pubmed/26537184

28. Barzallo Salazar MJ, Minkoff H, Bayya J, Gillett B, Onoriode H, Weedon J, Altshuler L, Fisher N. Influence of surgeon behavior on trainee willingness to speak up: a randomized controlled trial. 2014. Retrieved from PubMed database on August 9, 2016 available on http://wwwncbi-n/m-nihgov.eproxy2.lib.hku.hk/pubmed/?term=Influence+of+surgeon +behavior+on+trainee+willingness+to+speak+up\%3A+a+randomized +controlled+trial.

29. Muniak MA, Cochrane DD, Dijk VM, Hamilton A, Schwarz KWS, O'Connor PJ, Sahjpaul LR. What Would I Want For My Surgery? Healthc Q. 2014;17(4):7-9. doi:10.12927/hcq.2015.24124

30. Saufl NM. Patients encouraged to "Speak Up". 2003. Retrieved from ScienceDirect on December 20, 2015 available on http://ac.els-cdn.com. eproxy1.lib.hku.hk/S1089947203000054/1-s2.0-S1089947203000054-main. pdf?_tid=339caeb8-a6e5-11 e5-b6c0-00000aab0f27\&acdnat=1450594085_ daf5f5e7b7d3660645b216bf2d8000b7

31. Hrisos S, Thomson R. Seeing it from both sides: do approaches to involving patients in improving their safety risk damaging the trust between patients and healthcare professionals? An interview study. 2013. Retrieved from PubMed database on December 20, 2015 available on http://www-ncbi-nlm-nih-gov.eproxy1.lib.hku.hk/pmc/articles/ PMC3819291/pdf/pone.0080759.pdf 
32. Rance S, McCourt C, Rayment J, Mackintosh N, Carter W, Watson K, Sandall J. Women's safety alerts in maternity care: is speaking up enough? 2013. Retrieved from Quality and Safety BMJ on December 30, 2015 available on http://qualitysafety.bmj.com.eproxy1.lib.hku.hk/content/22/4/348.full.pdf+htm

33. Rainey $H$, Ehrich $\mathrm{K}$, Mackintosh N, Sandall J. The role of patients and their relatives in 'speaking up' about their own safety - a qualitative study of acute illness. 2015. Retrieved from Wiley Online Library on December 30 2015 available on http://onlinelibrary.wiley.com.eproxy1.lib.hku.hk/doi/10. 1111/hex.12044/epdf

34. Yule S, Parker HS, Wilkinson J, McKinley A, MacDonald J, Neill A, McAdam T. Coaching Non-Technical skills Improves Surgical Residents' Performance in a simulated Operating Room. 2015. Retrieved from ScienceDirect on January 11, 2016 available on http://ac.els-cdn.com.eproxy1.lib.hku.hk/ S1931720415001646/1-s2.0-S1931720415001646-main.pdf?_tid = f8182ee8b83d-11e5-978a-00000aab0f6c\&acdnat = 1452501380_1c753f32d5e57da4c0 ec3b70f60891ae

35. Schwappach DL, Gehring K. 'Saying it without words': a qualitative study of oncology staff's experiences with speaking up about safety concerns. 2014. Retrieved from PubMed database on December 15, 2015 available on http://www-ncbi-nlm-nih-gov.eproxy1.lib.hku.hk/pmc/articles/PMC4025461/ pdf/bmjopen-2013-004740.pdf

36. Lukewich J, Edge DS, Tranmer J, Raymond J, Miron J, Ginsburg L, VanDenKerkhof E. Undergraduate baccalaureate nursing students' selfreported confidence in learning about patient safety in the classroom and clinical settings: an annual cross-sectional study (2010-2013). 2015. Retrieved from ScienceDirect on December 9, 2015 available on http://ac. els-cdn.com.eproxy2.lib.hku.hk/S0020748915000115/1-s2.0S0020748915000115-main.pdf?_tid=57a98850-9e87-11e5-b37b00000aacb35f\&acdnat=1449674163_ac8953e72b910f831427ecaef7f489d5

37. Bowman C, Neeman N, Sehgal NL. Enculturation of unsafe attitudes and behaviors: student perceptions of safety culture. 2013. Retrieved from PubMed database on December 16, 2015 available on http://www-ncbi-nlm-nih-gov. eproxy1.lib.hku.hk/pmc/articles/PMC4024094/pdf/nihms-576215.pdf

38. Sayre MM, McNeese-Smith D, Leach LS, Phillips LR. An educational intervention to increase "speaking-up" behaviors in nurses and improve patient safety. 2012. Retrieved from Ovid database on December 20, 2015 available on http://ovidsp.tx.ovid.com.eproxy1.lib.hku.hk/sp-3.18.0b/ovidweb. cgi?WebLinkFrameset=1\&S=IACMFPMIICDDJILONCJKKBIBOGBHAA00\& returnUrl=ovidweb.cgi\%3f\%26Full\%2bText\%3dL\%257cS.sh.22.23\%257c0\% 257c00001786-201204000-00009\%26S\%3dIACMFPMIICDDJILONCJKKBIBO GBHAA00\&directlink=http\%3a\%2f\%2fgraphics.tx.ovid.com\%2fovftpdfs\% 2fFPDDNCIBKBLOIC00\%2ffs046\%2fovft\%2flive\%2fgv023\%2f00001786\% 2f00001786-201204000-00009.pdf\&filename $=A n+E d u c a t i o n a l+I n t e r v e n t i o n+$ to+Increase+\%22Speaking-Up\%22+Behaviors+in+Nurses+and+Improve+ Patient+Safety.\&pdf_key=FPDDNCIBKBLOIC00\&pdf_index=/fs046/ovft/live/ gv023/00001786/00001786-201204000-00009

39. O'Connor P, Byrne D, O'Dea A, McVeigh TP, Kerin MJ. "Excuse me:" teaching interns to speak up. 2013. Retrieved from PubMed database on December 16, 2015 available on http://www-ncbi-n/m-nih-gov.eproxy1.lib.hku.hk/ pubmed/24147354

40. Hughes MK, Benenson SR, Krichten EA, Clancy DK, Ryan PJ, Hammond C. A Crew Resource Management Program Tailored to Trauma Resuscitation Improves Team Behavior and Communication. 2014. Retrieved from ScienceDirect on December 15, 2015 available on http://www.sciencedirect. com.eproxy2.lib.hku.hk/science/article/pii/S1072751514003615

41. Kent $L$, Anderson $G$, Ciocca R, Shanks L, Enlow M. Effects of a senior practicum course on nursing students' confidence in speaking up for patient safety. 2015. Retrieved from PubMed Database on December 9, 2015 available on http://www-ncbi-nlm-nih-gov.eproxy2.lib.hku.hk/pubmed/ 25692337

42. Gupta RT, Sexton JB, Milne J, Frush DP. Practice and quality improvement: successful implementation of TeamSTEPPS tools into an academic interventional ultrasound practice. 2015. Retrieved from American Journal of Roentgenology on December 21, 2015 available on http://www.ajronline. org.eproxy2.lib.hku.hk/doi/pdf/10.2214/AJR.14.12775

43. Seiden SC, Galvan C, Lamm R. Role of medical students in preventing patient harm and enhancing patient safety. 2006. Retrieved from PubMed database on December 20, 2015 available on http://www-ncbi-nlm-nih-gov. eproxy1.lib.hku.hk/pmc/articles/PMC2564025/pdf/272.pdf

44. Reid J, Bromiley M. Clinical human factors: the need to speak up to improve patient safety. 2012. Retrieved from EBSCOhost database on December 8,
2015 available on http://web.a.ebscohost.com.eproxy2.lib.hku.hk/ehost/ pdfviewer/pdfviewer?sid = 8aec3763-ba8b-4a39-b4ef197977e423d3\%40sessionmgr4001\&vid = 8\&hid = 4212

45. PS 100 Introduction to Patient Safety, Lesson 3: A Call to Action — What YOU Can Do. Open School, Institute for Healthcare Improvement (IHI). Retrieved on January 10, 2016 from $1 \mathrm{H}$ available on http://app.ihi.org/Ims/ lessondetailview.aspx?LessonGUID=0a152256-edd5-4edd-8e1af947a71f8f1e\&CourseGUID=c67a038c-b021-43c3-b7b8-

f74e4ec303f4\&CatalogGUID=4cc435f0-d43b-4381-84b8-899b35082938

46. Lyndon A, Johnson MC, Bingham D, Napolitani PG, Joseph G, Maxfield DG, O'Keeffle DF. Transforming communication and safety culture in intrapartum care: a multi-organization blueprint. 2015. Retrieved from Ovid database on December 9, 2015 available on http://ovidsp.tx.ovid.com. eproxy2.lib.hku.hk/sp-3.17.0a/ovidweb.cgi?WebLinkFrameset=1\&S= IHEFFPEPEODDIJDINCJKGFDCGBCMAA00\&returnUrl=ovidweb.cgi $\% 3 f \%$ 26Full\%2bText\%3dL\%257cS.sh.22.23\%257c0\%257c00006250-20150500000006\%26S\%3dIHEFFPEPEODDIJDINCJKGFDCGBCMAA00\&directlink= http\%3a\%2f\%2fgraphics.tx.ovid.com\%2fovftpdfs\%2fFPDDNCDCGFDIEO 00\%2ffs046\%2fovft\%2flive\%2fgv023\%2f00006250\%2f00006250-

201505000-00006.pdf\&filename=Transforming+Communication+and+Safety +Culture+in+Intrapartum+Care\%3a+A+Multi-Organization+Blueprint.\&pdf_ key=FPDDNCDCGFDIEO00\&pdf_index=/fs046/ovft/live/gv023/00006250/ 00006250-201505000-00006

47. PS 102: Human Factors and Safety. Open School, Institute for Healthcare Improvement $(\mathrm{IHI})$. Retrieved on January 10, 2016 from $\mathrm{IH}$ available on http://app.ihi.org/Ims/coursedetailview.aspx?CourseGUID=0d1d53a1-1ec44065-8250-56247132fb9e\&CatalogGUID=4cc435f0-d43b-4381-84b8899b35082938\&LessonGUID=00000000-0000-0000-0000-000000000000

48. Lee SH, Kim JS, Jeong YC, Kwak DK, Chun JH, Lee HM. Patient safety in spine surgery: regarding the wrong-site surgery. 2013. Retrieved from PubMed database on December 16, 2015 available on http://www-ncbinlm-nih-gov.eproxy1.lib.hku.hk/pmc/articles/PMC3596588/pdf/asj-7-63.pdf

49. Banja JD, Craig K. Speaking up in case management, part II: implementing speaking up behaviors. 2010. Retrieved from Ovid database on December 18, 2015 available on http://ovidsp.tx.ovid.com.eproxy1.lib.hku.hk/ sp-3.18.0b/ovidweb.cgi?WebLinkFrameset=1\&S=HBKDFPPBFKDDNIMGNC JKJCGCENAPAA00\&returnUrl=ovidweb.cgi\%3f\%26Full\%2bText\%3dL \%257cS. sh.22.23\%257c0\%257c01269241-201009000-00003\%265\%3dHBKDFPPBFKDD NIMGNCJKJCGCENAPAA00\&directlink=http\%3a\%2f\%2fgraphics.tx.ovid. com\%2fovftpdfs\%2fFPDDNCGCJCMGFK00\%2ffs046\%2fovft\%2flive\% 2fgv025\%2f01269241\%2f01269241-201009000-00003.pdf\&filename= Speaking+Up+in+Case+Management\%2c+Part+II\%3a+Implementing +Speaking+Up+Behaviors.\&pdf_key=FPDDNCGCJCMGFKO0\&pdf_index=/ fs046/ovft/live/gv025/01269241/01269241-201009000-00003

50. Gauld R, Horsburgh S. Healthcare professional perspectives on quality and safety in New Zealand public hospitals: findings from a national survey. 2014. Retrieved from PubMed database on December 16, 2015 available on http://www-ncbi-nlm-nih-gov.eproxy1.lib.hku.hk/pubmed/24351789

51. Jones A, Kely D. Deafening silence? Time to reconsider whether organisations are silent or deaf when things go wrong. 2014. Retrieved from BMJ Quality and Safety database on December 20, 2015 available on http://qualitysafety. bmj.com.eproxy1.lib.hku.hk/content/23/9/709.full.pdf+html

52. Hospital Survey on Patient Safety Culture, The Agency for Healthcare Research and Quality (AHRQ). Retrieved on January 10, 2016 from http:// www.ahrq.gov/sites/default/files/wysiwyg/professionals/quality-patientsafety/patientsafetyculture/hospital/resources/hospscanform.pdf

53. The Safety Attitudes Questionnaire: psychometric properties, benchmarking data, and emerging research. The Agency for Healthcare Research and Quality (AHRQ). Retrieved on January 10, 2016 from https://psnet.ahrq.gov/ resources/resource/3601

54. Etchegaray JM, Thomas EJ. Engaging Employees: The Importance of HighPerformance Work Systems for Patient Safety. 2015. Retrieved from Ovid on December 21, 2015 available on http://ovidsp.tx.ovid.com.eproxy2.lib.hku.hk/ sp-3.18.0b/ovidweb.cgi?WebLinkFrameset $=1 \& S=$ FJPAFP ADKDDDJIHHNCJKPHIBCICNAA00\&returnUrl=ovidweb.cgi\%3f\%26Full\% 2bText\%3dL\%257cS.sh.22.23\%257c0\%257c01209203-20151200000007\%265\%3dFJPAFPADKDDDJIHHNCJKPHIBCICNAA00\&directlink= http\%3a\%2f\%2fgraphics.tx.ovid.com\%2fovftpdfs\%2fFPDDNCIBPHHHKD00\% 2ffs046\%2fovft\%2flive\%2fgv023\%2f01209203\%2f01209203-20151200000007.pdf\&filename=Engaging + Employees $\% 3 a++$ The+Importance+of +High-Performance+Work+Systems+for+Patient+Safety.\&pdf_ 
key=FPDDNCIBPHHHKD00\&pdf_index=/fs046/ovft/ive/gv023/01209203/ 01209203-201512000-00007

55. John O. Understanding and Improving Patient Safety: the Psychological, Social and Cultural Dimensions. J Health Organ Manag. 2009;23(6):581-96.

56. Rosenstein HA. 2015. Retrieved from PubMed database on January 11, 2016 available on Physician Disruptive Behaviors: Five Year Progress Report http:// www-ncbi-nlm-nih-gov.eproxy1.lib.hku.hk/pubmed/?term=Physician +Disruptive+Behaviors\%3A+Five+Year+Progress+Report

57. Law YB, Chan AE. The experience of learning to speak up: a narrative inquiry on newly graduated registered nurses. 2015. Retrieved from EBSCOhost database on December 8, 2015 available on http://web.a. ebscohost.com.eproxy2.lib.hku.hk/ehost/command/detail?sid=6902aa00c568-4f09-a856-1ede3e8a97e1\%40sessionmgr4002\&vid=1\&hid=4212

58. Schwaooach DLB, Gehring K. Frequency of and predictors for withholding patient safety concerns among oncology staff: a survey study. 2015. Retrieved from EBSCOhost database on December 8, 2015 available on http://web.a.ebscohost.com.eproxy2.lib.hku.hk/ehost/command/ detail?sid=8aec3763-ba8b-4a39-b4ef-197977e423d3\%40session mgr4001\&vid=12\&hid $=4212$

59. Putnam RL, Levy MS, Kellagher M C, Etchegaray MJ, Thomas JE, Kao SL, Lally PK, Tsao K. Surgical resident education in patient safety: where can we improve? 2015. Retrieved from ScienceDirect on December 9, 2015 available on http://ac.els-cdn.com.eproxy2.lib.hku.hk/ S0022480415007076/1-s2.0-S0022480415007076-main.pdf?_tid=80f698489e7c-1 1 e5-9e30-00000aab0f6c\&acdnat=1449669508_afc36f1 aa7a4340 c3201f7e7cea51a7f

60. Hemingway WM, O'Malley C, Silvestri S. Safety Culture and Care: A Program to Prevent Surgical Errors. 2015. Retrieved from ScienceDirect on December 15, 2015 available on http://www.sciencedirect.com.eproxy2.lib.hku.hk/ science/article/pii/S0001209215000034

61. Nancy YJ, Ryan D, Scott MC, Daniele B, Katerune O. Communication and psychological safety in veterans health administration work environments. 2014. Retrieved from ProQuest database on December 15, 2015 available on http://search.proquest.com.eproxy2.lib.hku.hk/docview/1633956087/ fulltextPDF?accountid $=14548$

62. Buetow $S$, Davis $R$, Callaghan $K$, Dovey $S$. What attributes of patients affect their involvement in safety? A key opinion leaders' perspective. 2013. Retrieved from PubMed database on December 16, 2015 available on http://www-ncbi-nlm-nih-gov.eproxy1.lib.hku.hk/pmc/articles/PMC3752058/ pdf/bmjopen-2013-003104.pdf

63. Garon M. Speaking up, being heard: registered nurses' perceptions of workplace communication. 2012. Retrieved from Wiley Online Library on December 17, 2015 available on http://onlinelibrary.wiley.com.eproxy1.lib. hku.hk/doi/10.1111/j.1365-2834.2011.01296.x/epdf

64. Entwistle VA, McCaughan D, Watt IS, Birks Y, Hall J, Peat M, Williams B, Wright J. Speaking up about safety concerns: multi-setting qualitative study of patients' views and experiences. 2010. Retrieved from Quality and Safety, BMJ on December 17, 2015 available on http://qualitysafety.bmj.com. eproxy1.lib.hku.hk/content/19/6/e33.full.pdf+html

65. Banja JD, Craig K. Speaking up in case management, part l: ethical and professional considerations. 2010. Retrieved from Ovid database on December 18, 2015 available on http://ovidsp.tx.ovid.com.eproxy1.lib.hku.hk/ sp-3.18.0b/ovidweb.cgi?WebLinkFrameset=1\&S=LOCNFPIBGODDNI BHNCJKIAGCIFOGAA00\&returnUrl=ovidweb.cgi\%3f\%26Full\%2bText\% 3dL\%257cS.sh.22.23\%257c0\%257c01269241-201007000-00003\%26S\% 3dLOCNFPIBGODDNIBHNCJKIAGCIFOGAA00\&directlink=http\%3a\%2f\% 2fgraphics.tx.ovid.com\%2fovftpdfs\%2fFPDDNCGCIABHGO00\%2ffs046\% 2fovft\%2flive\%2fgv025\%2f01269241\%2f01269241-201007000-00003.pdf \&filename $=$ Speaking + Up+in+Case+Management $\% 2 c+$ Part $+1 \% 3 a+$ Ethical +and+Professional+Considerations.\&pdf_key=FPDDNCGCIABHGO00\&pdf_ index=/fs046/ovft/live/gv025/01269241/01269241-201007000-00003

66. Donnelly FL, Dickerson MJ, Goodfriend AM, Muething ES. Improving Patient Safety in Radiology: Concepts for a Comprehensive Patient Safety Program. 2010. Retrieved from ScienceDirect on December 18, 2015 available on http://ac.els-cdn.com.eproxy1.lib.hku.hk/S0887217109001048/1-s2.0S0887217109001048-main.pdf? tid=59ef588c-a4e1-11e5-988d00000aacb362\&acdnat=1450372529_a861769f49c2a5175ba4f239c7e7f065

67. Bromiley M, Mitchell L. Would you speak up if the consultant got it wrong? .. and would you listen if someone said you'd got it wrong? 2009. Retrieved from PubMed database on December 18, 2015 available on http://www-ncbi-n/m-nih-gov.eproxy1.lib.hku.hk/pubmed/19908670
68. Blanco M, Clarke JR, Martindeli D. Wrong site surgery near misses and actual occurrences. 2009. Retrieved from ScienceDirect on December 18, 2015 available on http://ac.els-cdn.com.eproxy1. lib.hku.hk/S0001209209004815/1s2.0-S0001209209004815-main.pdf?_tid=5d6698a2-a4e8-11e5-a8d600000aacb35f\&acdnat $=1450375541$ _ 7 e4a641f15d015cd003e686d95c8c340

69. Pian-Smith MC, Simon R, Minehart RD, Podraza M, Rudolph J, Walzer T, Raemer D. Teaching residents the two-challenge rule: a simulation-based approach to improve education and patient safety. 2009. Retrieved from ScienceDirect on December 20, 2015 available on http://ovidsp.tx.ovid.com. eproxy1.lib.hku.hk/sp-3.18.0b/ovidweb.cgi?WebLinkFrameset=1\&S=PBAL FPHLNMDDJIPNNCJKEBMCEDIHAA00\&returnUrl=ovidweb.cgi $\% 3 f \%$ 26Full\%2bText\%3dL\%257cS.sh.22.23\%257c0\%257c01266021-20090042000004\%26S\%3dPBALFPHLNMDDJIPNNCJKEBMCEDIHAA00\&directlink= http\%3a\%2f\%2fgraphics.tx.ovid.com\%2fovftpdfs\%2fFPDDNCMCEBPNNMO0\% 2ffs047\%2fovft\%2flive\%2fgv024\%2f01 266021\%2f01266021-200900420-00004. pdf\&filename=Teaching+Residents+the+Two-Challenge+Rule\%3a+A +Simulation-Based+Approach+to+Improve+Education+and+Patient+Safety. \&pdf_key=FPDDNCMCEBPNNM00\&pdf_index=/fs047/ovft/live/gv024/ 01266021/01266021-200900420-00004

70. Rainer J. Speaking up: factors and issues in nurses advocating for patients when patients are in jeopardy. 2015. Retrieved from Ovid database on December 20, 2015 available on http://ovidsp.tx.ovid.com.eproxy1.lib.hku.hk/ sp-3.18.0b/ovidweb.cgi?WebLinkFrameset=1\&S=HMOKFPDJJJDD JIMJNCJKLAOBHAGMAA00\&returnUrl=ovidweb.cgi\%3f\%26Full\%2b Text\%3dL\%257cS.sh.22.23\%257c0\%257c00001786-20150100000010\%26S\%3dHMOKFPDJJJDDJIMJNCJKLAOBHAGMAA00\&directlink= http\%3a\%2f\%2fgraphics.tx.ovid.com\%2fovftpdfs\%2fFPDDNCOBLAMJJJ00\% 2ffs046\%2fovft\%2flive\%2fgv023\%2f00001786\%2f00001786-201501000-00010. pdf\&filename $=$ Speaking + Up\%3a+Factors + and + Issues + in + Nurses +Advocating+for+Patients+When+Patients+Are+in+Jeopardy.\&pdf_ key=FPDDNCOBLAMJJJ00\&pdf_index=/fs046/ovft/live/gv023/00001786/ 00001786-201501000-00010

71. Abdi Z, Delgoshaei B, Ravaghi H, Abbasi M, Heyrani A. The culture of patient safety in an Iranian intensive care unit. 2015. Retrieved from Wiley Online Library on December 20, 2015 available on http://onlinelibrary.wiley.com. eproxy1.lib.hku.hk/doi/10.1111/jonm.12135/epdf

72. Spruce L. Back to basics: preventing surgical site infections. 2014. Retrieved from ScienceDirect on December 20, 2015 available on http://ac.els-cdn. com.eproxy2.lib.hku.hk/S0001209214001525/1-s2.0-S0001209214001525main.pdf?_tid=8151605a-a72f-11e5-b573-00000aacb35e\&acdnat=1 450625998_42fe8e193b250afe40a245dd0c3abf70

73. Liao JM, Thomas EJ, Bell SK. Speaking up about the dangers of the hidden curriculum. 2014. Retrieved from Health Affairs on December 21, 2015 available on http://content.healthaffairs.org/content/33/1/168.full.pdf+html

74. Sur DM, Schindler $N$, Singh P, Angelos $P$, Langerman A. Young surgeons on speaking up: when and how surgical trainees voice concerns about supervisors' clinical decisions. 2015. Retrieved from ScienceDirect on December 29, 2015 available on http://ac.els-cdn.com.eproxy1.lib.hku.hk/ s0002961015006121/1-s2.0-S0002961015006121-main.pdf?_tid=d6634f68ae05-11e5-98ac-00000aacb361\&acdnat=1451377760_cb6de2b497be336 Od9c1 bb548631f0e3

75. Rabøl LI, Andersen ML, Ostergaard D, Bjørn B, Lilja B, Mogensen T. Republished error management: Descriptions of verbal communication errors between staff. An analysis of 84 root cause analysis-reports from Danish hospitals. 2011. Retrieved from PubMed database on January 11, 2016 available on http://www-ncbi-n/m-nih-gov.eproxy1.lib.hku.hk/pubmed/ ?term=Republished+error+management\%3A+Descriptions+of+verbal +communication+errors+between+staff.+An+analysis+of+84+root+cause tanalysis-reports+from+Danish+hospitals

76. Rabøl LI, Andersen ML, Ostergaard D, Bjørn B, Lilja B, Mogensen T. Republished error management: Descriptions of verbal communication errors between staff. An analysis of 84 root cause analysis-reports from Danish hospitals. 2011. Retrieved from Postgrad Medical Journal, BMJ on December 31, 2015 available on http://pmj.bmj.com.eproxy2.lib.hku.hk/ content/87/1033/783.full.pdf+html 